\title{
Dual damage criteria in a crash stop
}

DOI:

https://doi.org/10.1016/j.ijmecsci.2020.105732

\section{Document Version}

Accepted author manuscript

Link to publication record in Manchester Research Explorer

\section{Citation for published version (APA):}

Yang, C., \& Li, Q. M. (2020). Dual damage criteria in a crash stop. International Journal of Mechanical Sciences, 183, 1-13. [105732]. https://doi.org/10.1016/j.ijmecsci.2020.105732

\section{Published in:}

International Journal of Mechanical Sciences

\section{Citing this paper}

Please note that where the full-text provided on Manchester Research Explorer is the Author Accepted Manuscript or Proof version this may differ from the final Published version. If citing, it is advised that you check and use the publisher's definitive version.

\section{General rights}

Copyright and moral rights for the publications made accessible in the Research Explorer are retained by the authors and/or other copyright owners and it is a condition of accessing publications that users recognise and abide by the legal requirements associated with these rights.

\section{Takedown policy}

If you believe that this document breaches copyright please refer to the University of Manchester's Takedown Procedures [http://man.ac.uk/04Y6Bo] or contact uml.scholarlycommunications@manchester.ac.uk providing relevant details, so we can investigate your claim.

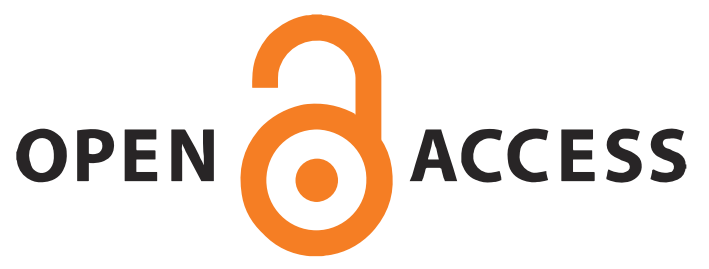




\section{Dual damage criteria in a crash stop}

Chengxing Yang, Q. M. Li*

Department of Mechanical, Aerospace and Civil Engineering, School of Engineering, The University of Manchester, Manchester M13 9PL, UK

\section{ABSTRACT}

This study proposes a method to apply dual criteria for the assessment of product damage based on the deceleration signal in a crash-stop incident. To evaluate the shock effects, a procedure is proposed to decompose the original crash signal into two components, i.e. an equivalent crash signal and a residual shock signal. The characteristics of crash signals are analysed in both time and frequency domains. It is found that the equivalent crash signal can represent the original crash signal if the dominant frequency $\left(f_{n}\right)$ of the product structure is relatively lower than the effective frequency $\left(f_{s}\right)$ of the crash signal, i.e. $\frac{f_{n}}{f_{s}} \leq \frac{1}{5}$. Otherwise, the original crash signal should be used in the assessment of product damage if $\frac{f_{n}}{f_{s}}>\frac{1}{5}$. The dual damage criteria method is proposed by combing the maximum-acceleration vs. velocity-change $\left(A_{\max }-\Delta \mathrm{V}\right)$ diagram and shock response spectrum (SRS), i.e. the former can offer a lower bound of damage boundary on $A_{\max }-\Delta \mathrm{V}$ diagram while the latter can define an upper bound of damage boundary on SRS graph. The method of dual damage criteria is illustrated numerically using two types of cantilever beams, as an example. The proposed method can be applied with the critical SRS $\left(S_{c}\right)$ method recommended in ASTM D3332-99 for the packaging design and test, and may also be considered in the design and test of other impact energy absorbers in a crash-stop incident.

Keywords: Crash-stop incident; Damage boundary criteria; Acceleration-velocity change $\left(A_{\max }-\Delta \mathrm{V}\right)$ diagram; Shock response spectrum (SRS)

*Corresponding author.

E-mail address: qingming.li@manchester.ac.uk (Q.M. Li). 


\section{Introduction}

Crash-stop phenomena exist widely in various engineering applications, such as product fragility and packaging [1], 'soft landing' of re-entry capsule and spacecraft [2,3], impact protection of nuclear waste flask [4], design of crushable structures [5], or impact energy absorber (IEA) [6], in various transportation vehicles (e.g., automotive, rail, ship, aircraft). These applications concern the survivable crash-stop of the carrier container for the safety of its occupants (e.g., passenger, product or good). A typical container can be generically simplified into two main parts, i.e. the protector (e.g., packaging, IEA, cushion) and the protected component to host the occupant, as illustrated in Fig. 1. Usually, the protector is crushable to limit the impact force and absorb impact energy to maintain a relatively rigid envelope of survivable space and reduce the shock effects transmitted to the occupant [7]. The transmitted shock effects are usually characterised by the specified deceleration-time history applied to the occupant, which can be used to analyse occupant's response [8].

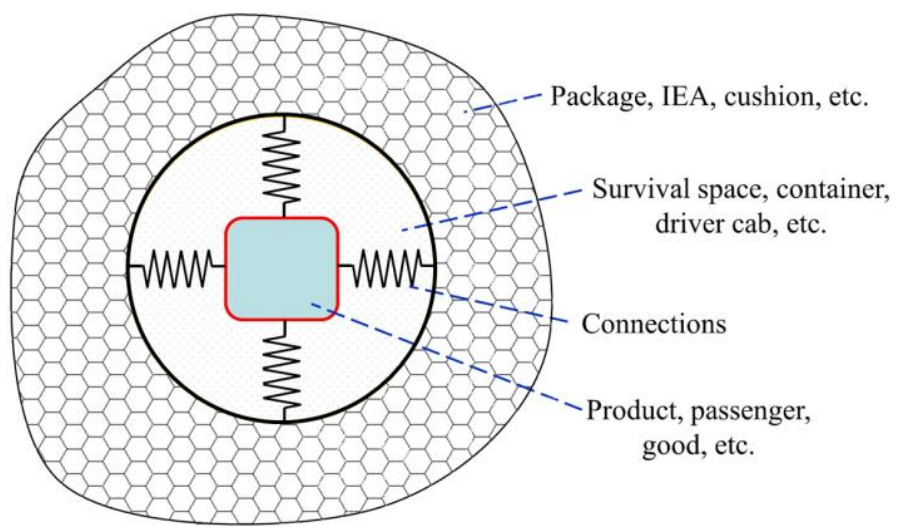

Fig. 1. A generic container in a crash-stop incident, which can be simplified into two main parts, i.e. the protector (e.g., packaging, IEA, cushion) and the protected component (e.g., product, passenger, good).

The damage or injury of an occupant in an impact incident has been evaluated by the maximum acceleration against velocity change graph (i.e. $A_{\max }-\Delta \mathrm{V}$ diagram), as proposed in [9], where a rectangular acceleration-time history was used to derive a conservative $A_{\max }-\Delta \mathrm{V}$ diagram. The derivation of $A_{\max }-\Delta \mathrm{V}$ diagram has the same nature and procedure as the derivation of pressureimpulse ( $p-i)$ diagram, a widely applied method to assess the damage of structures subjected to blast loading [10-12]. The American Society for Testing and Materials (ASTM) incorporated the $A_{\max }{ }^{-}$ $\Delta \mathrm{V}$ diagram into the Standard Test Methods for Mechanical Shock Fragility of Products (ASTM D3332-99) [13]. Mechanical shock in a structure is usually characterised by high frequency oscillations over short time duration. Because the high frequency oscillation cannot be completely represented by the velocity change, $A_{\max }-\Delta \mathrm{V}$ diagram alone cannot describe the crash effect. 
Mechanical shock can be produced either by the stress wave propagations and reflections in the structural domain due to the application of an intensive transient loading, or directly by a transient loading with high frequency oscillations due to the structural behaviour of packaging protector (e.g., progressive crushing) [14-16]. Shock response spectrum (SRS), introduced initially by Biot [17], is an efficient approach to assess the severity of shock environment (e.g., [18,19]), which has different types of indicators, i.e. absolute acceleration (AA), pseudo acceleration (PA), pseudo velocity (PV), acceleration pseudo velocity (APV) and relative displacement (RD), as summarised in [20-22]. Although SRS was discussed in [9], it was only considered for the damage of products (or devices) when product's dominant natural frequency $\left(f_{n}\right)$ is higher than the dominant frequency of the deceleration-time history. Later on, the concept of critical SRS $\left(S_{c}\right)$ derived from trapezoidal acceleration-time history was used in the packaging design of product protection [23], which was adopted in ASTM D3332-99 [13], as summarised in Appendix. Qian et al. [24] experimentally and numerically conducted shock tests on a packaged washing machine based on ASTM D3332-99. Shock test data showed that the packaging design using the $A_{\max }-\Delta \mathrm{V}$ diagram is conservative, while the assessment method based on the $S_{c}$ method may provide support for the development of more effective packaging system. In other words, it is possible to design the cushion to transmit higher accelerations than the critical maximum acceleration $\left(\mathrm{A}_{\mathrm{max}, \mathrm{cr}}\right)$ without causing damage to the product. Although the ASTM D3332-99 has been taken as a testing standard in packaging industry, its valid application range did not seem to have been clearly stated because only several idealised crash signals were considered. In addition, the procedure to apply joint $A_{\max }-\Delta \mathrm{V}$ diagram and the $S_{c}$ method to assess the product damage is not detailed in ASTM D3332-99 [13].

On the other hand, vehicle crashworthiness can be generally considered as the fragility problem of a packaged product where the 'packaging' is replaced by the passive IEA and the product represents the carried passenger or goods. Several crashworthiness indices have been proposed to evaluate the crashing performance of an IEA, e.g., energy absorption (EA), specific energy absorption (SEA), peak crushing force (PCF), mean crushing force (MCF), crushing force efficiency, stroke efficiency, total efficiency, and energy-absorbing effectiveness factor [25-29], which only focus on IEA's overall crashworthiness performance with little concern of shock oscillation. Consequently, product damage and human injury criteria in a crash incident are usually assessed using the parameters determined by the overall crashworthiness responses of the IEA, which is irrelevant to the oscillation of acceleration-time history.

The shock environments of vehicles during normal transportation are characterised in [30-32]. Nevertheless, limited works were reported on the shock analysis in vehicle crashworthiness. Foley and Gens [33] applied SRS method to describe the mechanical vibration and shock environment in 
normal rail and truck transportation (e.g., run in, run out and crossing rail switches, bridges and highway underpasses). Later, Magnuson [34] found that the time durations of the mechanical shock in normal rail transportation are similar to those in rail coupling or shunting; but the magnitude of the coupling shock is severer than the magnitudes of the mechanical shocks in normal rail transportation because the coupling event is a designated low-velocity impact. When two acceleration-time curves are similar in time domain, they may have large difference in frequencydomain, as shown in [35] for two acceleration-time curves in crash incidents even if they both meet the impact condition specified in relevant standard (ECE R17) [36]. Therefore, it was concluded that the SRS method is a useful tool for distinguishing the potential damage or injury caused by similar crash signals in time domain [35], which demonstrates the importance of shock analysis in a crashworthiness design. It is beneficial to consider product/occupant safety as a general crash-stop problem in both packaging and vehicle crashworthiness due to their similarity.

The objective of the present work is to develop a method for the assessment of structural damage based on the crash signal in a general crash-stop incident. Without causing confusion and for the simplification, the term of 'damage' may generally include structural damage and human injury, the term 'structure' may include product, device, structural component and human body or part, and the term of 'acceleration' may generally include deceleration, in the rest of this paper if no particular notation is given. Section 2 discusses the characteristics of a crash signal, the procedure of signal decomposition and the calculation of characteristic frequency ratios. Section 3 focuses on the structural damage assessment criteria using $A_{\max }-\Delta \mathrm{V}$ diagram and SRS method. Section 4 validates the proposed damage criteria by two types of cantilever beams with relatively low and high natural frequencies.

\section{Crash signal characteristics}

\subsection{Signal decomposition}

Generally, the crush load-time history of a package/IEA can be related to an acceleration-time history at a representative location of the protected object. Without losing generality, we consider the original crash signal (OCS) in the form of acceleration-time history $(A(t))$. In order to assess the shock effects, we herein decompose the OCS into two components, $A_{1}(t)$ and $A_{2}(t)$, i.e.

$A(t)=A_{1}(t)+A_{2}(t)$

where $A_{1}(t)$ is the equivalent crash signal (ECS) whose velocity-change $\Delta \mathrm{V}$ is identical to that of $A(t) ; A_{2}(t)=A(t)-A_{1}(t)$ is the residual shock signal (RSS) whose integral of acceleration over time equals zero. It is noted that the term of 'equivalent crash wave' used in some publications [37] has the same meaning of ECS. 

satisfying the above requirements can be easily identified. As an example, the OCS of an object attached to a thin-walled tube subjected to an axial collision can be divided into an equivalent square signal (ESS) and a RSS in Fig. 2. The $\Delta \mathrm{V}$ of ESS equals that of OCS, while the integration of RSS is zero. The OCS and ESS are shown in Fig. 2(a) while the RSS is shown in Fig. 2(b). $t_{d}$ denotes the overall time duration of the shock signal.

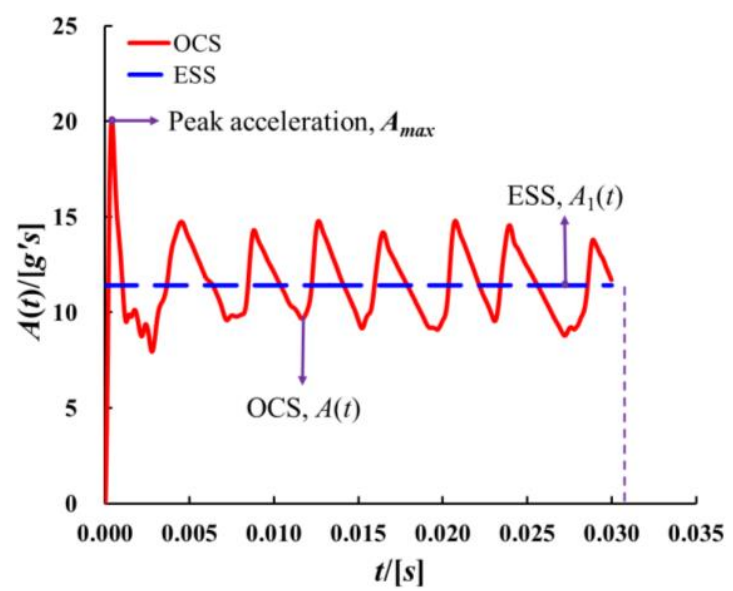

(a)

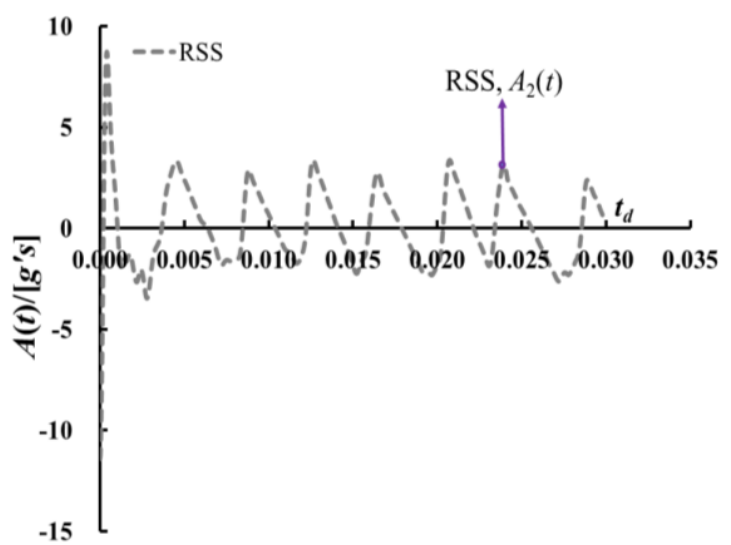

$t /[s]$

(b)

Fig. 2. Typical load curve associated with an axially crushed thin-walled cylinder tube: $(a)$ OCS and ESS; (b) RSS

For more complex OCSs shown in Fig. 3(a), the following general procedure is recommended. Firstly, a low-pass filter with a given frequency $\left(f_{L}\right)$ is used to remove high frequency oscillations in the OCS. Then, the filtered signal is compensated by a vertical translation to meet the requirement of same velocity-change, i.e.

$A_{3}=\frac{1}{t_{d}}\left\{\int_{0}^{t_{d}} A(t) d t-\int_{0}^{t_{d}}\left[\left.A(t)\right|_{\text {low-pass filtered by } f_{L}}\right] d t\right\}$

where the $\Delta \mathrm{V}$ of $A_{3}(t)$ equals the difference between the $\Delta \mathrm{V}$ of $A(t)$ and the $\Delta \mathrm{V}$ of the low-pass filtered curve; $f_{L}$ is determined by

where $f_{1}$ and $f_{2}$ are the nonzero frequencies corresponding to the highest and the next highest amplitudes from the FFT of OCS with satisfying the condition of $f_{1}<f_{2}$. For example, the typical acceleration curve associated with a frontal barrier crash test of a vehicle is shown in Fig. 3(b) [38] and its corresponding FFT graph is plotted in Fig. 3(d), where $f_{1}=11 \mathrm{~Hz}, f_{2}=22 \mathrm{~Hz}$. Therefore, $f_{L}=$ $16.5 \mathrm{~Hz}$ according to Eq. (3). 


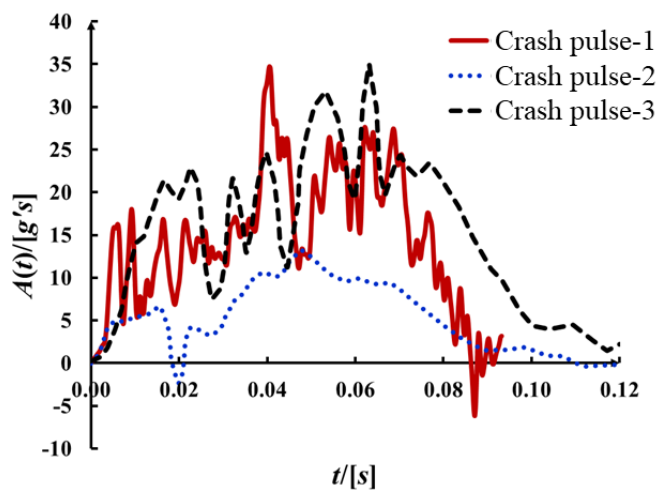

(a)

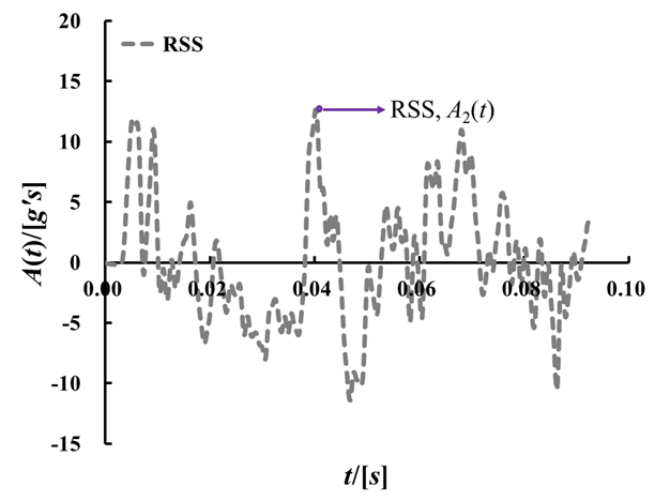

(c)

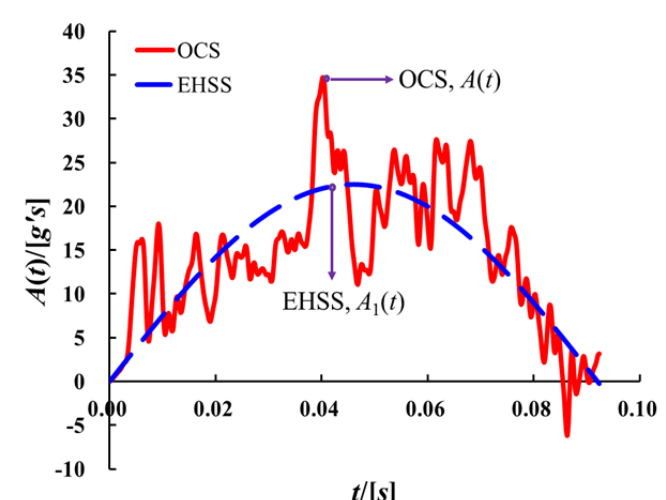

(b)

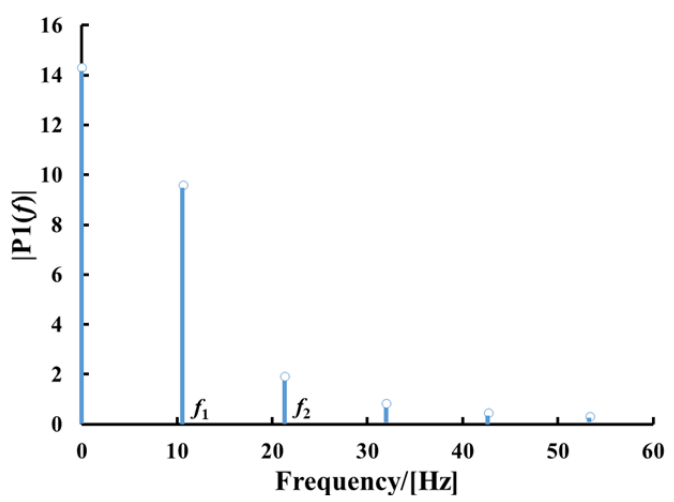

(d)

Fig. 3. (a) Typical acceleration curves associated with a vehicle crash where crash pulse-1 was extracted from a small four door sedan in [38] (the location of accelerometer was unspecified); crash pulse-2 was extracted from the unbelted occupant in [37]; crash pulse-3 was extracted from the B-pillar of a truck in [37]. (b) (c) Typical acceleration curve associated with frontal barrier crash test of a vehicle [38]: OCS, the equivalent half-sine signal (EHSS) and RSS. (d) The fast Fourier transform (FFT) of the OCS shown in Fig. 3(b).

\subsection{Characteristic frequency ratios}

To compare the structural responses to OCS and ECS and to explore the effect of RSS, a singledegree-of-freedom (SDOF) model is employed. The product is idealised as a lumped mass $(m)$ with elastic coefficient $(k)$, damping coefficient $(c)$ and natural frequency $\left(f_{n}=\frac{1}{2 \pi} \sqrt{\frac{k}{m}}\right)$, which is loaded by the acceleration-time history acting on the base, i.e. $\ddot{x}(t)=A(t)$. The responses of the SDOF, e.g., the absolute acceleration $(\ddot{y})$ and relative displacement $(z=y-x)$, can be described by

$m \ddot{z}+c \dot{z}+k z=-m \ddot{x}$

Solutions of Eq. (4) can be easily obtained by Duhamel integration, which will not be repeated here. According to structural dynamics [39], the transmissibility (TR) for a damped SDOF system subjected to a harmonic excitation is given by 
157

$T R=\left\{\frac{1+\left(2 \xi \frac{\omega}{\omega_{n}}\right)^{2}}{\left[1-\left(\frac{\omega}{\omega_{n}}\right)^{2}\right]^{2}+\left(2 \xi \frac{\omega}{\omega_{n}}\right)^{2}}\right\}^{\frac{1}{2}}$

158 where $\omega_{n}=2 \pi f_{n}=\sqrt{\frac{k}{m}} ; \omega$ is the angular frequency of harmonic excitation; $\xi$ is damping ratio $159\left(c=2 \xi \omega_{\mathrm{n}}\right)$. The displacement transmissibility is identical to the acceleration transmissibility, which 160 is plotted in Fig. 4 for $\xi=0$ and 0.05 [39].

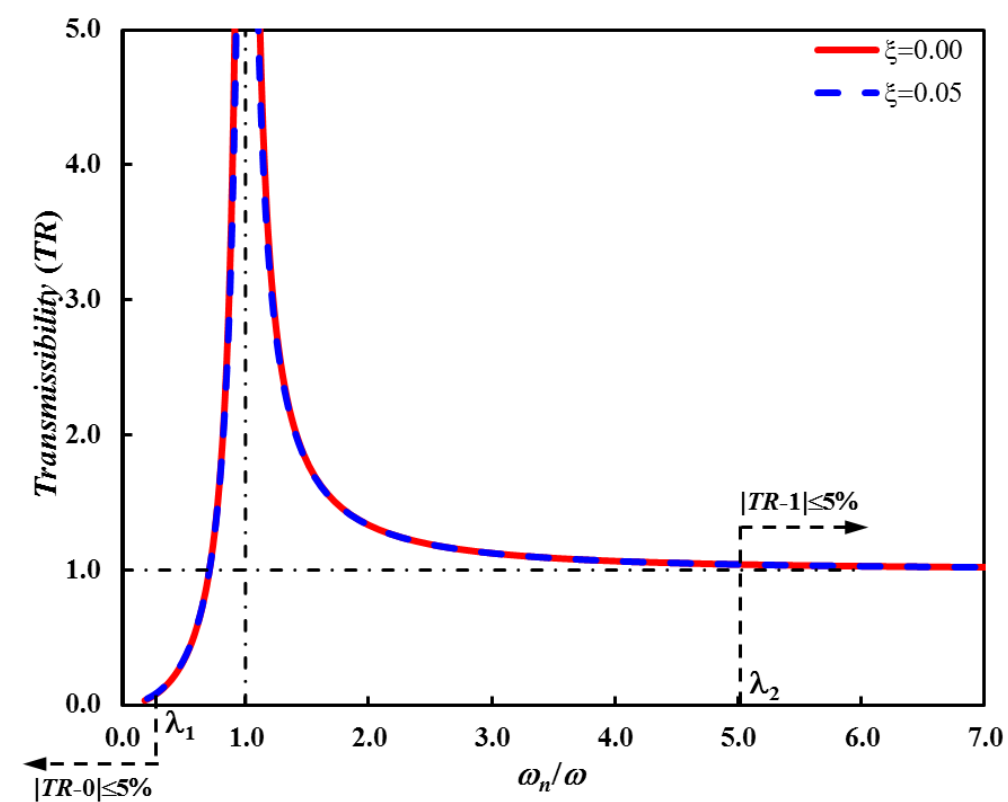

Fig. 4. Transmissibility of a SDOF system subjected to a harmonic base excitation.

As shown in Fig. 4, the transmissibility is zero as $\frac{\omega_{n}}{\omega} \rightarrow 0$, peaks at $\frac{\omega_{n}}{\omega} \approx 1$, and approaches unity as $\frac{\omega_{n}}{\omega} \rightarrow \infty$. Therefore, two characteristic frequency ratios, i.e. $\lambda_{1}=\frac{\omega_{n}}{\omega_{1}}$ and $\lambda_{2}=\frac{\omega_{n}}{\omega_{2}}$ can be determined by $\lambda_{1}=\max \left\{\lambda\right.$ with $\left.\|T R-0\|<\varepsilon_{1}\right\}$ and $\lambda_{2}=\min \left\{\lambda\right.$ with $\left.\|T R-1\|<\varepsilon_{2}\right\}$, respectively. Normally, a $5 \%$ relative accuracy is sufficient for structural design [3], and thus, $\lambda_{1} \approx 1 / 5$ and $\lambda_{2} \approx 5$ are obtained respectively from Fig. 4 when $\varepsilon_{1}=\varepsilon_{2}=0.05$ are taken.

Considering an array of SDOF models subjected to the same base excitation, a SRS curve can be obtained. Fig. 5 presents the normalised absolute acceleration SRS (AASRS) curves drived from six typical ideal crash pulses, i.e. ESS, equivalent positive triangular signal (EPTS), equivalent negative triangular signal (ENTS), equivalent isosceles triangular signal (EITS), EHSS and equivalent haversine signal (EHVS) [37]. These six ideal crash signals have identical $\Delta \mathrm{V}$ and $t_{\mathrm{d}}$. The signal's effective frequency is defined as the lowest dominant frequency in this study, i.e. $f_{s}=$ $f_{1}$ in Fig. 3(d) as an example. Newton [9] found that the AASRS for a given shape of the crash signal is approximately a straight line through the origin when $\frac{f_{n}}{f_{s}}<\frac{1}{6} \approx 0.167 .0 .167 f_{s}$ is the lower 
knee frequency on the SRS of OCS, which is close to the characteristic ratio of $\frac{1}{5}=0.2$ obtained from Fig. 4 using 5\% relative accuracy (i.e. the characteristic ratio value may change when the relative accuracy is changed). Signal's effective frequency and effective time duration are defined as $\frac{A_{\max }}{\Delta \mathrm{V}}$ and $\frac{\Delta \mathrm{V}}{A_{\max }}$, respectively, in $[9,40]$ for given $\mathrm{A}_{\max }$ and $\Delta \mathrm{V}$.

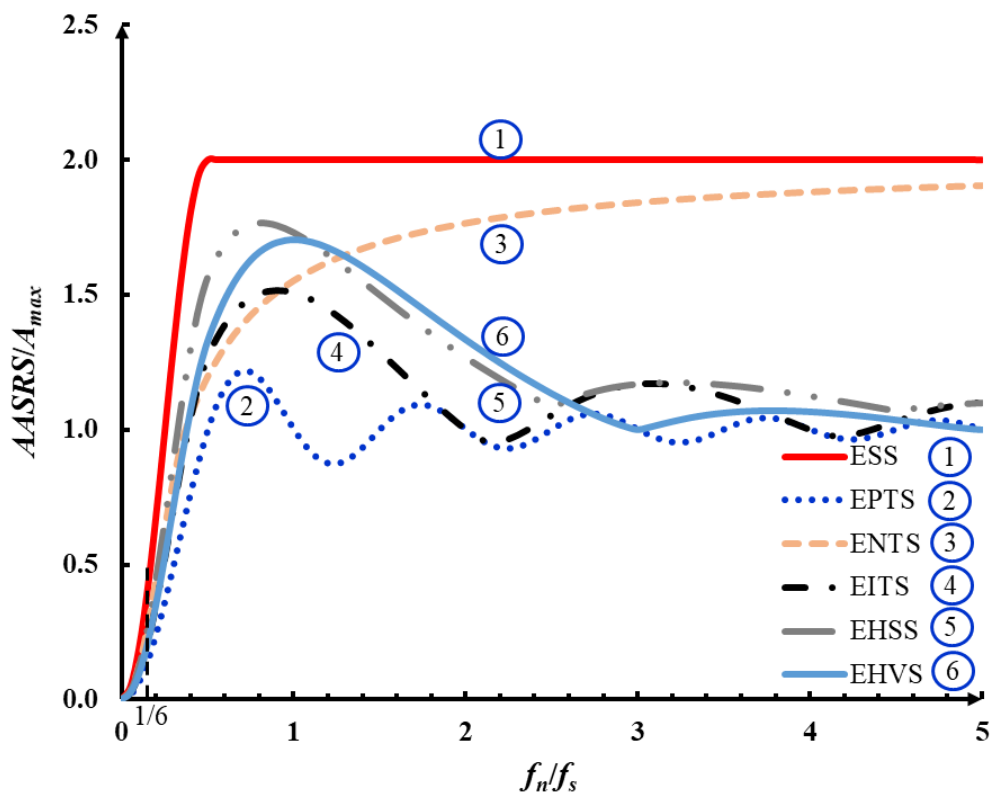

Fig. 5. The normalised AASRS curves for an umdamped SDOF system subjected to various crash signals.

To validate the characteristic ratios $\left(\lambda_{1}\right.$ and $\left.\lambda_{2}\right)$, three types of SDOF models with relatively low, medium and high natural frequencies are discussed. The typical acceleration curve associated with the frontal barrier crash test of a vehicle in Fig. 3(b) is taken as the base excitation, whose effective frequency equals the reciprocal of time duration, i.e. $f_{s}=f_{1}=\frac{1}{t_{d}}$ in this study (Fig. 3(d)). The corresponding results are tabulated in Table 1.

Table 1. Results of the SDOF models with relatively low, medium and high natural frequencies when subjected to base excitations $(\ddot{\boldsymbol{x}}(\boldsymbol{t})=$ OCS, ECS and RSS, respectively) in Fig. 3(b) (c).

\begin{tabular}{|c|c|c|c|c|c|c|}
\hline \multirow{2}{*}{$\begin{array}{l}\text { Natural frequency, } \\
f_{n}(\mathrm{~Hz})\end{array}$} & \multirow{2}{*}{$\frac{f_{n}}{f_{s}}$} & \multicolumn{4}{|c|}{ Structural response } & \multirow{2}{*}{$\begin{array}{l}\text { Relative difference } \\
\text { between OCS and ECS }\end{array}$} \\
\hline & & & from OCS & from ECS & from RSS & \\
\hline \multirow{2}{*}{2.146} & \multirow{2}{*}{$\frac{1}{5}$} & $|\ddot{y}|_{\max }[\mathrm{g}]$ & 13.8 & 13.8 & 0.215 & $0 \%$ \\
\hline & & $|z|_{\max }[\mathrm{mm}]$ & 549 & 548 & 8.08 & $0 \%$ \\
\hline \multirow{2}{*}{10.730} & \multirow{2}{*}{1} & $|\ddot{y}|_{\max }[\mathrm{g}]$ & 31.7 & 36.5 & 5.06 & $15.14 \%$ \\
\hline & & $|z|_{\max }[\mathrm{mm}]$ & 68.2 & 78.7 & 10.5 & $15.40 \%$ \\
\hline 53.650 & 5 & $|\ddot{y}|_{\max }[\mathrm{g}]$ & 42.7 & 23.5 & 26.1 & $-44.96 \%$ \\
\hline
\end{tabular}




$|z|_{\max }[\mathrm{mm}] \quad 3.67 \quad 2.0200 \quad 2.24 \quad-44.96 \%$

From Table 1, it is obvious that the structural responses rely on the natural frequency of the structure, i.e. (i) when $f_{\mathrm{n}}$ is relatively low $\left(\frac{f_{n}}{f_{s}} \leq \frac{1}{5}\right)$, negligible differences are observed between the results derived from OCS and ECS. For example, if $f_{\mathrm{n}}=2.146 \mathrm{~Hz}$ or $\frac{f_{n}}{f_{s}}=\frac{1}{5}$, differences of $|\ddot{y}|_{\max }$ and $|z|_{\max }$ are both close to 0 ; (ii) when $f_{\mathrm{n}}$ equals $f_{s}$ (or they are generally in the same order), obvious differences can be found between the results from OCS and ECS, e.g., if $f_{\mathrm{n}}=10.73 \mathrm{~Hz}$ or $\frac{f_{n}}{f_{s}}=1$, differences of $|\ddot{y}|_{\max }$ and $|z|_{\max }$ are $15.14 \%$ and $15.40 \%$, respectively; (iii) when $f_{\mathrm{n}}$ is relatively high $\left(\frac{f_{n}}{f_{s}} \geq 5\right)$, significant differences are captured between the responses resulted from OCS and ECS, e.g., if $f_{\mathrm{n}}=53.65 \mathrm{~Hz}$ or $\frac{f_{n}}{f_{s}}=5$, differences of $|\ddot{y}|_{\max }$ and $|z|_{\max }$ are both $44.96 \%$.

It shows that OCS and ECS result in very similar responses in a SDOF model with relatively low frequency, no matter what the shape of crash signal is. It implies that ECS is able to represent the OCS for assessing the damage of structures with relatively low natural frequencies while the RSS has great effect on the responses of structures having relatively high natural frequencies, which demonstrates the neccesities of the signal decomposition discussed in Section 2.1 and the determination of the characteristic frequency ratios. More accurate criteria for structural damage assessment can be established by employing the $A_{\max }-\Delta \mathrm{V}$ diagram and SRS graph with the consideration of characteristic frequency ratios, as shown in next section.

\section{Structural damage boundary criteria}

\section{$3.1 f_{n} / f_{s} \leq 1 / 5$}

As discussed in Section 2, ECS is able to represent the OCS well when $\frac{f_{n}}{f_{s}} \leq \frac{1}{5}$. The ESS-based $\mathrm{A}_{\max }-\Delta \mathrm{V}$ diagram is introduced in this case to assess the structural damage. In general, structural damage is usually defined by an overall displacement failure criterion in $p-i$ diagram [11], thus, the isodamage boundary in an $\mathrm{A}_{\max }-\Delta \mathrm{V}$ diagram can also be determined by the maximum relative displacement $\left(z_{\max }\right)$. However, this does not prevent the use of other failure criteria if they are more representative and available, e.g., the damage boundary based on yield stress $\left(\sigma_{y}\right)$ is presented in

214 Section 4. There are three main advantages for the use of $A_{\max }-\Delta V$ diagram with signal 215 decomposition, i.e. 
(i) $A_{\max }-\Delta V$ diagram can be employed for quick assessment because it only requires the information of the crash signal (i.e. no structural information is needed). If an isodamage boundary in the form of $\mathrm{A}_{\max }-\Delta \mathrm{V}$ diagram is obtained, the crash signal is represented by a point $\left(\mathrm{A}_{\max }, \Delta \mathrm{V}\right)$ on the diagram. Then, it is easy to judge whether the point falls in the damage region or non-damage region.

(ii) It is usually hard to replicate OCS in laboratory. However, it is relatively easier to generate the filtered ECS by available equipment (e.g., shaker table), which can produce the same damage level as that produced by OCS.

(iii) Although SRS can also be used to assess the structural damage [20], and a particular relationship between SRS and $A_{\max }-\Delta V$ diagram can be derived for a given signal (e.g., rectangular signal in [9]) based on SDOF, $A_{\max }-\Delta V$ diagram is not restricted to SDOF. Like a $p-i$ diagram, $A_{\max }-\Delta V$ diagram derived using SDOF model can be applied to multi-degree-of-freedom (MDOF) models and real structures in simulations, experiments and practical loading scenarios. The $A_{\max }-\Delta V$ diagram based on MDOF and simulation is discussed in Section 4. for a given crash signal (i.e. acceleration-time history herein) when $z_{\max }<z_{c r}$. $z_{c r}$ denotes the critical relative displacement of a structure associated with a given damage level. By following the same procedure for the derivation of $p-i$ diagram [11], two non-dimensional quantities are defined to determine the normalised maximum relative displacement, $z_{\max } / z_{c r}$.

which defines all points, $(a, v)$, on an isodamage curve for the given damage level prescribed by the critical relative displacement. The ideal isodamage boundary derived from a monotonicallydecreasing crash signal is presented in Fig. 6 to illustrate the general characteristics of the $a-v$ diagram. 


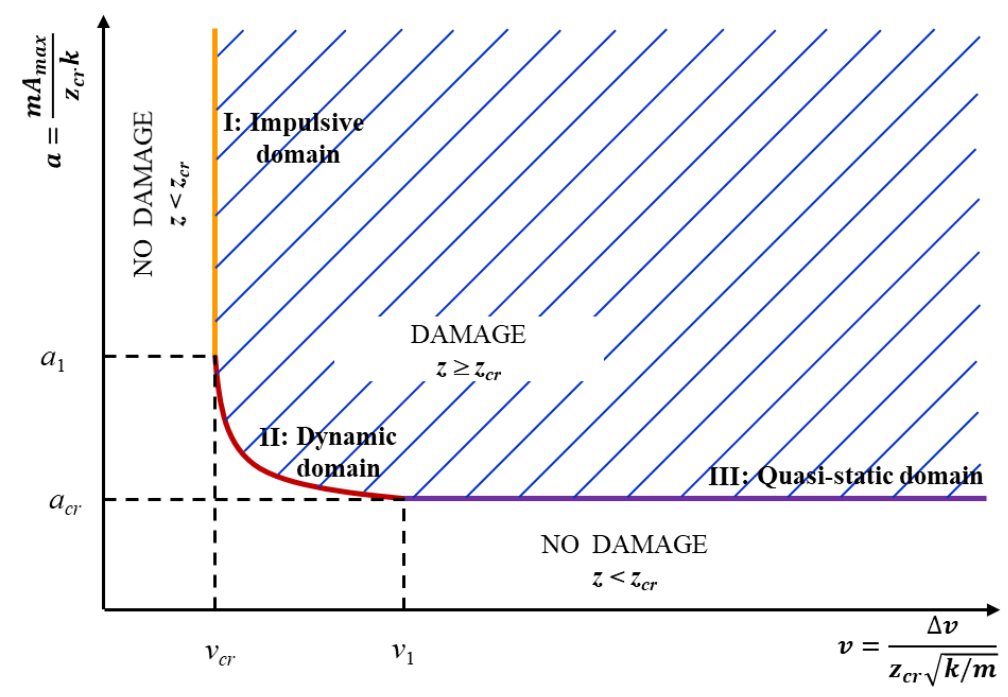

Fig. 6. The ideal isodamage boundary on the $a-v$ diagram.

The isodamage boundary has two asymptotes ( $a_{\mathrm{cr}}$ and $v_{\mathrm{cr}}$, as normalised critical maximum acceleration and critical velocity change), and can be divided into three regimes, i.e.

- Regime I: $a>a_{1}, v \approx v_{\mathrm{cr}}=\lim _{\mathrm{a} \rightarrow \infty}[g(a, v)=1]$

- Regime II: $a \leq a_{1}$ and $v \leq v_{1}$, structural damage is controlled by both $a$ and $v$, and

- Regime III: $v>v_{1}, a \approx a_{\mathrm{cr}}=\lim _{v \rightarrow \infty}[g(a, v)=1]$

$a_{1}$ and $v_{1}$ are the threshold values to distinguish Regimes I, II, and III on the $a$-v diagram, which are determined by accuracy requirements of $v_{1}=\min \left\{v\right.$ with $\left.\left\|v-v_{\text {cr }}\right\|<\varepsilon_{l}\right\}$ and $a_{1}=\min \left\{a\right.$ with $\left.\left\|a-a_{\text {cr }}\right\|<\varepsilon_{2}\right\}$, respectively. Again, we take $5 \%$ relative accuracy, i.e. $\varepsilon_{l}=\varepsilon_{2}=0.05$. For an undamped SDOF system subjected to ESS, the ratio between $a_{1}$ and $a_{\mathrm{cr}}$ equals 2 [40] and the ratio between $v_{1}$ and $v_{\mathrm{cr}}$ equals $\frac{\pi}{2}$ [9]. Regimes I, II and III represent impulsive, dynamic and quasi-static regimes, respectively [11]. acceleration and critical velocity change of the $A_{\max }-\Delta V$ diagram. If the average acceleration is introduced as 


$$
A_{\text {avg }} \leq\left(\frac{1}{\pi}\right) \cdot A_{\max , c r} \cdot\left(\frac{f_{n}}{f_{s}}\right)^{-1}
$$

Since the asymptote $v=v_{c r}$ of the $a-v$ diagram in Regime I applies to different crash signals $[39,40]$, the ideal ESS can be used to determine $v_{c r}$. In addition, $A_{a v g}$ is the same as $A_{\max }$ for ESS. Therefore, under the condition of $\frac{f_{n}}{f_{s}} \leq \frac{1}{5}$, no damage assessment is required if the $A_{\text {avg }}$ of OCS is lower than $\left(\frac{1}{\pi}\right) \cdot A_{\max , c r} \cdot\left(\frac{f_{n}}{f_{s}}\right)^{-1}$.

The $\mathrm{A}_{\max }-\Delta \mathrm{V}$ diagram or the normalised $a-v$ diagram introduced here can still be adopted in the following section, but its effectiveness is questionable as shown in Section 4. Besides, the SRS can also be used when $\frac{f_{n}}{f_{s}} \leq \frac{1}{5}$ to construct the upper bound of damage boundary, which will be introduced in the following section where the dual damage criteria are proposed.

\section{$3.2 f_{n} / f_{s}>1 / 5$}

As shown in Table 1, the high frequency oscillations in OCS have significant influence on the responses of structures having relatively high natural frequencies. Obvious differences could be observed between the structual responses derived from OCS and ECS, i.e. ECS is unable to represent OCS effectively. SRS is a widely adopted method for the evaluation of the severity of shock environment. SRS is defined as the maximum responses of a series of SDOF systems having the same damping, but different natural frequences, to a given transient shock signal. When $\frac{f_{n}}{f_{s}}>\frac{1}{5}$, $A_{\max }-\Delta V$ diagram can still be used for the assessment of damage under certain conditions while SRS should be introduced to supplement the assessment of damage caused by high frequency oscillatory shock effect. Therefore, dual damage criteria by combining $A_{\max }-\Delta V$ diagram and SRS graphs should be considered

The $a-v$ diagram with $z_{c r}$ damage level derived from six ideal crash signals is presented in Fig. 7. It can be found that the rectangular shaped signal, i.e. ESS, forms the most conservative boundary in Regimes II and III, because ESS defines the lowest $\mathrm{A}_{\max }$ for given $\Delta \mathrm{V}$ on $a-v$ diagram comparing with crash signals having other shapes. In addition, the $\mathrm{A}_{\max }$ of a measured base excitation (i.e. the crash signal) may be influenced by other factors, e.g., noise, sampling frequency and signal filtering. Therefore, $\mathrm{A}_{\max }-\Delta \mathrm{V}$ diagram (or $a-v$ diagram) based on ESS was recommended as a conservative damage diagram in packaging industry [13]. It should be noted that the maximum responsive acceleration of the SDOF system is approximately the maximum acceleration of the base excitation 
for high-frequency structures [20], which reduces the conservative extent of the ESS-based $A_{\max }{ }^{-}$ $\Delta \mathrm{V}$ diagram. The advantage of ESS-based $\mathrm{A}_{\max }-\Delta \mathrm{V}$ diagram is that it can be adopted for the initial quick assessment. If the base excitation, represented by a point $\left(\mathrm{A}_{\max }, \Delta \mathrm{V}\right)$ or $(a, v)$, falls into the non-damage region, then the structure is safe. Otherwise, further damage assessment with the aid of SRS method is necessary.

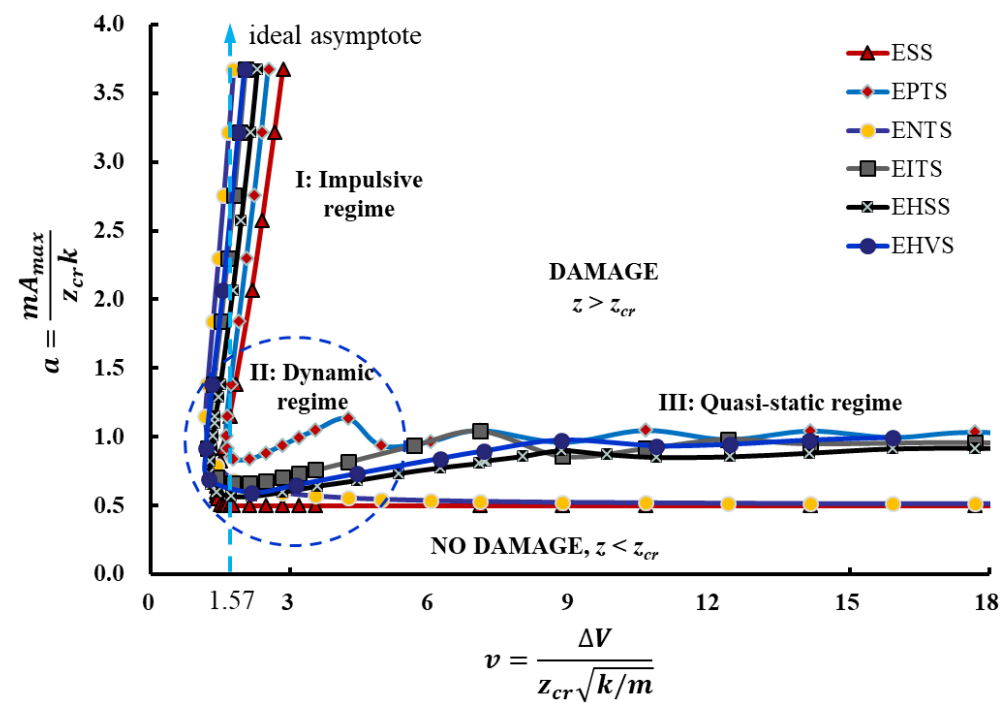

Fig. 7. The normalised $a-v$ diagrams of six ECSs with various shapes.

SRS is currently the standard method for quantifying the severity of mechanical shock events. It uses the responses of standarised structures (SDOF oscillators) to the base excitation for the assessment of shock severity rather than using the base excitation signal directly. As it is mentioned in Section 3.1, it is usually hard to reproduce the complex OCS (see Fig. 3(a)) in a laboratory. Thus, establishing the damage boundary in SRS graph based on the exact OCS is nearly impossible. But the decomposed smooth ECS whose $\triangle \mathrm{V}$ is identical to that of OCS, and the oscillating RSS whose $\Delta \mathrm{V}$ is zero, can be fairly easily reproduced without losing their shock features and be repeated in laboratory. According to the distributive law of convolution, the SRS damage boundary based on the critical loadings associated with ECS and RSS signals can give an upper bound of the SRS damage boundary for OCS, i.e.

$\mathrm{SRS}(\mathrm{OCS}) \leq \mathrm{SRS}(\mathrm{ECS})+\mathrm{SRS}(\mathrm{RSS})$

The upper bound of SRS damage boundary will be shown later by examples in Section 4 (Fig. 16). Three types of SRS curves, i.e. pseudo-acceleration SRS (PASRS), pseudo-velocity SRS (PVSRS), and relative displacement SRS (RDSRS) (see [20]), for an undamped SDOF model where PASRS $=$ AASRS have following relationships [20]

$$
\lg (P A S R S)-\lg \left(2 \pi f_{n}\right)=\lg (P V S R S)=\lg \left(2 \pi f_{n}\right)+\lg (R D S R S)
$$


PVSRS can be plotted on a 4-coordinate graph according to Eq. (12) where the iso-RDSRS, 313 iso-PVSRS and iso-PASRS lines have $45^{\circ}, 0^{\circ}$, and $-45^{\circ}$ slopes, respectively. The upper bound of 314 PVSRS damage boundary can be constructed as the summation of PVSRS curves derived from 315 critical ECS and RSS signals (Eq. (11)), which are respectively obtained by varying the peak 316 accelerations of ECS and RSS signals while keeping the time duration unchanged until structural 317 damage occurs. The PVSRS can also be adopted in the situation when $\frac{f_{n}}{f_{s}} \leq \frac{1}{5}$ to construct the upper 318 bound of damage boundary, although ECS is able to represent OCS well in this situation (see Section 4). The ESS-based $S_{c}$ method in ASTM D3332-99 [13] may also be adopted here to construct the lower bound in PVSRS graph, which may reduce the conservativeness of ESS-based $A_{\max }-\Delta V$ diagram. This procedure will be followed in Section 4 when the damage boundaries are constructed for a fully clamped beam as an example. The PVSRS curves of six typical ideal ECSs on 4coordinate graph are shown in Fig. 8. Both Figs. 5 and 8 show that ESS predicts the largest response, and therefore, gives the most conservative damage prediction when compared with other idealised ECS. It should be noted that other types of SRS may be selected for the $S_{c}$ method, as indicated in Appendix.

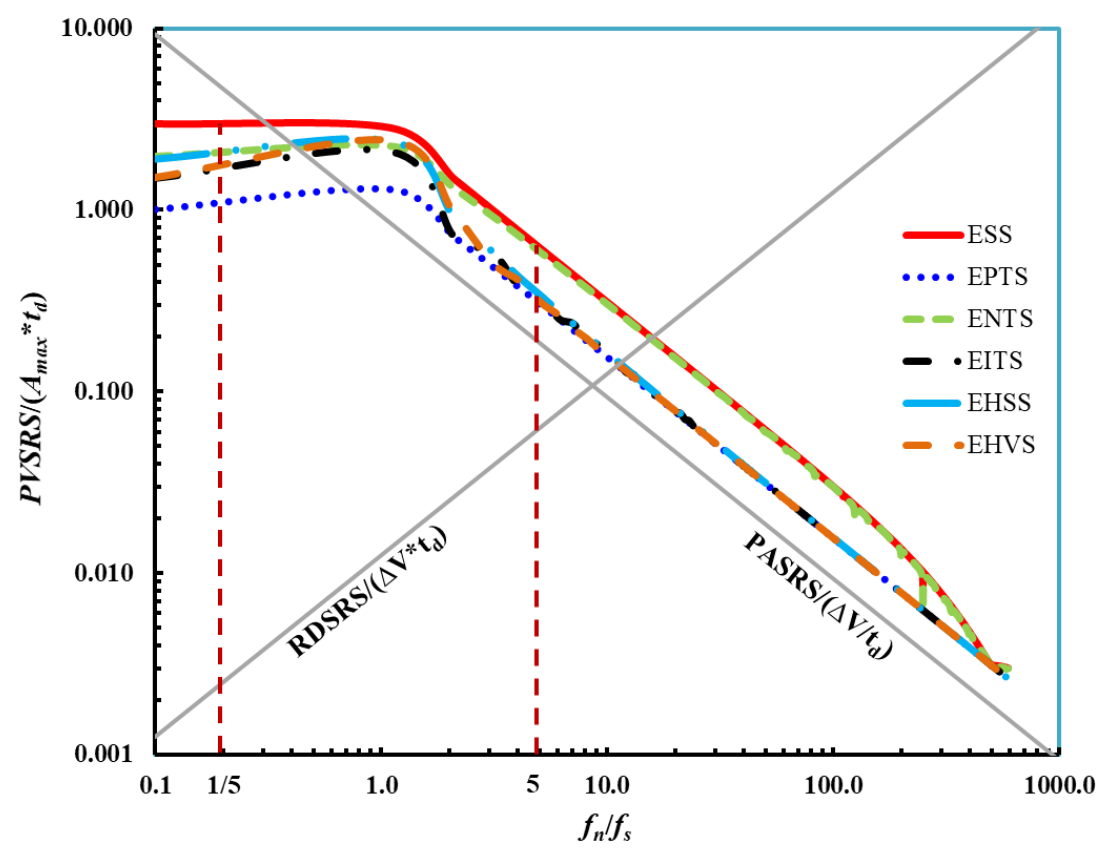

Fig. 8. Normalised PVSRS of various crash signals on a 4-coordinate graph.

330 if following two conditions are satisfied, i.e. (i) $\frac{f_{n}}{f_{s}} \leq \frac{1}{5}$, and (ii) $A_{\text {avg }} \leq\left(\frac{1}{\pi}\right) \cdot A_{\max , c r} \cdot\left(\frac{f_{n}}{f_{s}}\right)^{-1}$.

331 Otherwise, for $\frac{f_{n}}{f_{s}}>\frac{1}{5}$, the ECS cannot represent the OCS, and the OCS should be assessed. In either 
case, it is easier and cheaper to reproduce the smooth ECS and oscillatory RSS signals in laboratory when their shock features are kept in comparison with the reproduction of more complex OCS signals. It should be mentioned that the method proposed here is applicable to the crash signals in a crash stop characterised by a finite velocity change and $A(t) \geq 0$, which covers most cases of vehicle crash and packaging requirements. In other words, the $\Delta V$ of the crash signal is a monotonically increasing function of time. Pyroshock, ballistic shock and navy shock signals are not dominated by velocity change, and therefore, are out of the scope of this study.

\section{Validation of the damage boundary criteria}

The method of dual damage criteria is proposed for various crash-stop incidents in package droping and vehicle crash etc., as discussed in Section 1. A frontal barrier crash test of a vehicle [38] is taken to illustrate and demonstrate the signal decomposition and damage assessment. A cantilever beam with multiple natural frequencies is taken as a generic representative of the onboard product or occupant, which subjects base excitations $(\ddot{x}(t))$ from the vehicle (see Fig. 9(a)). The IEA and crushable structure, similar to the cushioning material in a package dropping senary, determine the OCS to the cantilever beam. The highly oscillatory signal in Fig. 3(b) (c) is used as an example of base excitations, which has been decomposed into the smooth $A_{1}(t)$ (i.e. the EHSS with $\Delta \mathrm{V} \neq 0$ ) and the oscillatory $A_{2}(t)$ (i.e. the RSS with $\Delta \mathrm{V}=0$ ) by following the procedure of signal decomposition in Section 2. The RSS illustrated in Fig. 3(c) inherits the high oscillation from OCS, because it is obtained by subtracting EHSS from OCS. The scaled crash signals (SCSs) are shown in Fig. 9(b) (c), with their key parameters summarised in Table 2 .

Two types of cantilever beams with relatively low $\left(\frac{f_{n}}{f_{s}} \approx \frac{1}{5}\right)$ and high $\left(\frac{f_{n}}{f_{s}} \approx 5\right)$ dominant natural frequencies are considered. The geometry and physical properties of these two cantilever beams are tabulated in Table 3 together with the lowest five natural frequencies for each beam. To judge the "significance" of a vibration mode, the modal participation factor $(r)$ [41] is calculated and its values are tabulated in Table 3. Then, the $f_{n}$ is taken as the structure's dominant natural frequency having the highest value of modal participation factor. Therefore, $f_{n}=f_{n 1}$ for both beam I and beam II in this study. To evaluate the potential damage of the beam due to the base excitation, the dual criteria are adopted to assess the damage of structures with different values of $\frac{f_{n}}{f_{s}}$. The $\mathrm{A}_{\max }-\Delta \mathrm{V}$ diagram is employed to build the lower bound of damage boundary, while the PVSRS graph is chosen to construct the upper bound of damage boundary. 


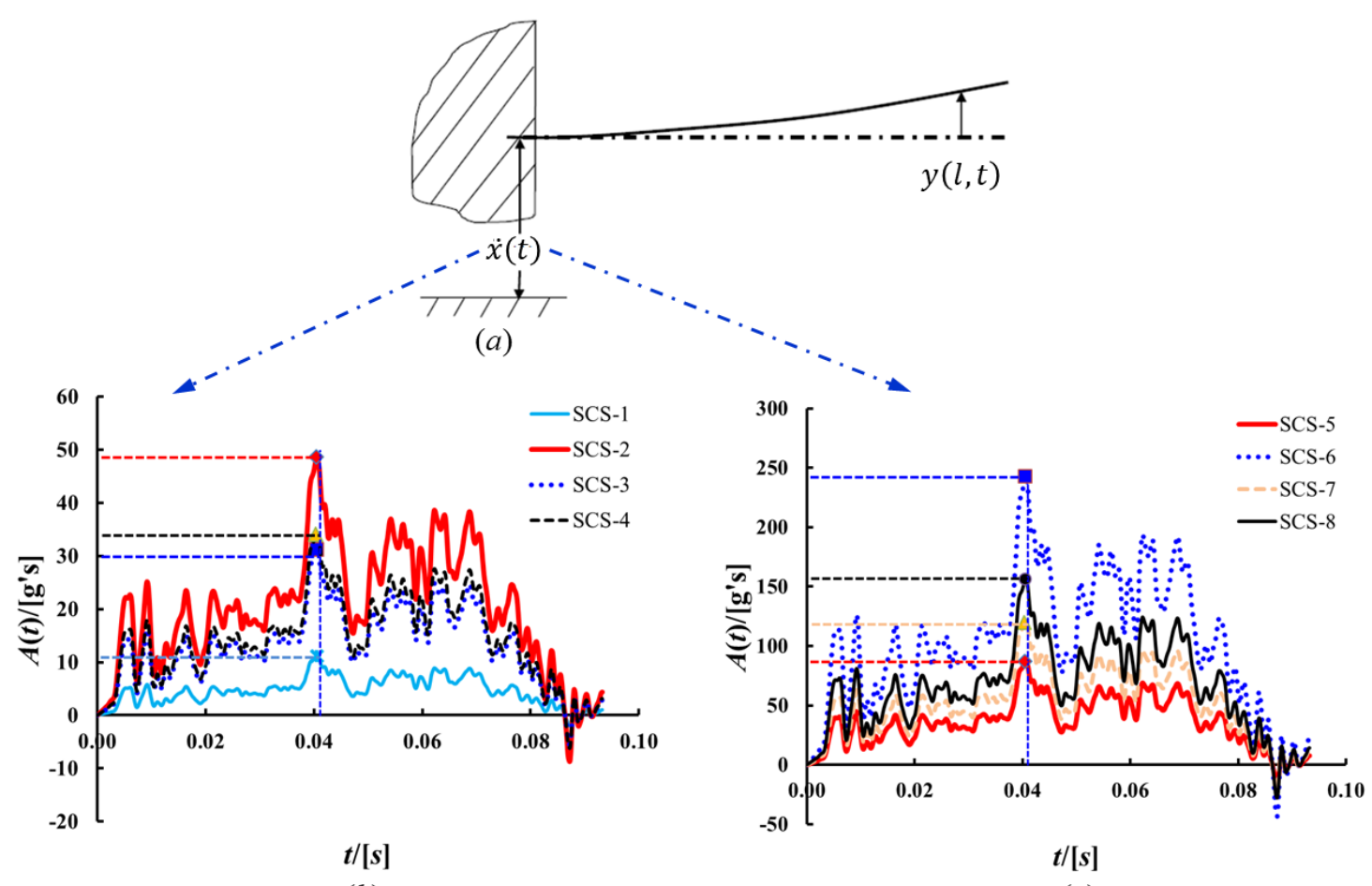

363 Fig. 9. (a) Illustration of a cantilever beam subjected to base excitation; $(b) \sim(c)$ Scaled crash signals (SCSs) with

364 the same shape as OCS in Fig. 3(b): (b) SCS-1 to SCS-4 that beam I is subjected to; (c) SCS-5 to SCS-8 that beam 365 II is subjected to.

Table 2. Key parameters of SCSs in Fig. $9(b) \sim(c)\left(f_{s}=10.73 \mathrm{~Hz}\right)$.

\begin{tabular}{ccccc}
\hline Base excitation, $\ddot{x}(t)[\mathrm{g}]$ & Scaled factor, $\alpha[-]$ & $\mathrm{A}_{\max }[\mathrm{g}]$ & $t_{d}[\mathrm{~s}]$ & $\Delta \mathrm{V}[9.8 \mathrm{~m} / \mathrm{s}]$ \\
\hline SCS-1 & 0.323 & 11.202 & 0.09324 & 0.431 \\
SCS-2 & 1.4 & 48.615 & 0.09324 & 1.872 \\
SCS-3 & 0.9 & 31.253 & 0.09324 & 1.203 \\
SCS-4 & 1 & 34.725 & 0.09324 & 1.337 \\
SCS-5 & 2.5 & 86.812 & 0.09324 & 3.343 \\
SCS-6 & 7.0 & 243.075 & 0.09324 & 9.360 \\
SCS-7 & 3.5 & 121.537 & 0.09324 & 4.680 \\
SCS-8 & 4.5 & 156.262 & 0.09324 & 6.017 \\
\hline
\end{tabular}

$\frac{f_{n}}{f_{s}}$

Geometry and physical properties

\begin{tabular}{ccccccccc}
\hline Width $\times$ & Area moment & Density, $\rho$ & Elastic & Yield & Poisson's & Viscous & Natural & Modal \\
Length $\times$ & of inertia, $I_{m}$ & {$\left[\mathrm{~kg} / \mathrm{m}^{3}\right]$} & modulus, & stress, $\sigma_{y}$ & ratio, $v[-]$ & damping & frequencies & participation \\
\hline
\end{tabular}




\begin{tabular}{|c|c|c|c|c|c|c|c|c|c|}
\hline & $\begin{array}{l}\text { Thickness } \\
{\left[\mathrm{mm}^{3}\right]}\end{array}$ & {$\left[\mathrm{mm}^{4}\right]$} & & $E_{0}[\mathrm{GPa}]$ & [MPa] & & ratio, $\xi[-]$ & {$[\mathrm{Hz}]$} & factor [-] \\
\hline Beam & $100 \times$ & 8333.333 & 2770 & 71 & 280 & 0.30 & 0 & $f_{n 1}=2.154$ & $r_{1}=1.82$ \\
\hline \multirow[t]{4}{*}{ I } & $1950 \times$ & & & & & & & $f_{n 2}=13.465$ & $r_{2}=-1.01$ \\
\hline & 10 & & & & & & & $f_{n 3}=37.762$ & $r_{3}=0.59$ \\
\hline & & & & & & & & $f_{n 4}=74.055$ & $r_{4}=-0.42$ \\
\hline & & & & & & & & $f_{n 5}=122.406$ & $r_{5}=0.33$ \\
\hline Beam & $100 \times$ & 8333.333 & 2770 & 71 & 280 & 0.30 & 0 & $f_{n 1}=53.858$ & $r_{1}=0.81$ \\
\hline \multirow[t]{4}{*}{ II } & $390 \times$ & & & & & & & $f_{n 2}=336.615$ & $r_{2}=-0.45$ \\
\hline & 10 & & & & & & & $f_{n 3}=944.052$ & $r_{3}=0.27$ \\
\hline & & & & & & & & $f_{n 4}=1851.38$ & $r_{4}=-0.19$ \\
\hline & & & & & & & & $f_{n 5}=3060.14$ & $r_{5}=0.15$ \\
\hline
\end{tabular}

\subsection{Beam I with $f_{n} / f_{s} \approx 1 / 5$}

The first natrural frequency of beam I is $2.154 \mathrm{~Hz}$, i.e. $\frac{f_{n}}{f_{s}} \approx \frac{1}{5}$. Responses of the cantilever

371 beam are tabulted in Table 4, including maximum absolute acceleration, maximum relative

372 displacement and relative differences between the results derived from OCS and ECS. From Table

3734 , it can be found that the $|z|_{\max }$ values derived from OCS and ECS are close to each other,

374 although relatively larger difference is observed for $|\ddot{y}|_{\max }$ values. Such observations are slightly

375 different from the results of SDOF in Table 1. Since the damage boundary is generally controlled

376 by the maximum relative displacement for low-frequency structures [20], the results in Table 4

377 support the proposed characteristic frequency ratio in Section 2.

378 Table 4. Results of the cantilever beam I with $\frac{f_{n}}{f_{s}} \approx \frac{1}{5}$ when subjected to base excitations in Fig. 3(b) (c).

\begin{tabular}{|c|c|c|c|c|c|}
\hline \multirow{2}{*}{$\begin{array}{c}\text { Natural frequencies of } \\
\text { Beam I }[\mathrm{Hz}]\end{array}$} & \multicolumn{4}{|c|}{ Structural response } & \multirow{2}{*}{$\begin{array}{c}\text { Relative difference } \\
\text { between OCS and ECS }\end{array}$} \\
\hline & & from OCS & from ECS & from RSS & \\
\hline \multicolumn{6}{|l|}{$f_{n 1}=2.154$} \\
\hline$f_{n 2}=13.465$ & $|\ddot{y}|_{\max }[\mathrm{g}]$ & 32.41 & 25.09 & 33.30 & $-22.59 \%$ \\
\hline \multicolumn{6}{|l|}{$f_{n 3}=37.762$} \\
\hline$f_{n 4}=74.055$ & $|z|_{\max }[\mathrm{mm}]$ & 863.40 & 873.90 & 15.80 & $1.22 \%$ \\
\hline$f_{n 5}=122.406$ & & & & & \\
\hline
\end{tabular}

Structural damage (including failure) is usually determined by a local damage criterion based on critical stress (strain), or an overall damage criterion based on critical acceleration or displacement at a selected reference point of a structure. It should be noted that the material damage 
associated with microscale mechanisms is not considered. To build the damage boundary, the yield stress $\left(\sigma_{y}\right)$ of cantilever beam is defined as the critical stress, i.e. $\sigma_{\mathrm{cr}}=\sigma_{y}=280 \mathrm{MPa}$. When anywhere of the beam becomes yielded, the loading is defined as the critical loading (i.e. critical crash signal). To construct the conservative isodamage boundary, the base excitation in the form of rectangular shaped pulse is varied by changing its time duration $\left(t_{d}\right)$ and magnitude $\left(\mathrm{A}_{\max }\right)$.

The finite element analysis is carried out in commercial FE code ANSYS ${ }^{\circledR}$. The number of solid elements of beam I is 600, as shown in Fig. 10(a). One side of the beam is fixed and subjects to base excitation while the other side is free (see Fig. 9). A bilinear curve is used to model the elastic-plastic behaviour of metallic material (see Table 3). The mesh sensitivity convergence is examined using different meshes, and the results show that the displacement of the free end has only $0.9 \%$ relative difference when the element number is doubled. Therefore, the current mesh scheme is sufficient for the analysis. The FE model of this cantilever beam can be validated by theoretical analysis with Matlab code [42,43]. As shown in Fig. 10(b), high consistency is observed in the relative displacement derived from FE modelling and theoretical calculation, respectively, when cantilever beam I subjects to the OCS of Fig. 3(b).

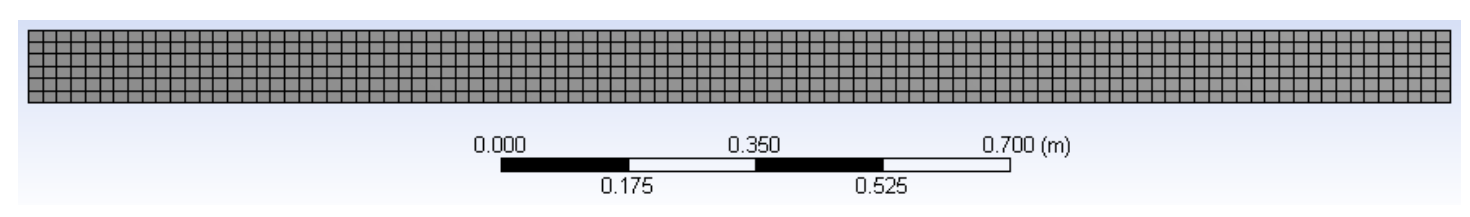

(a)

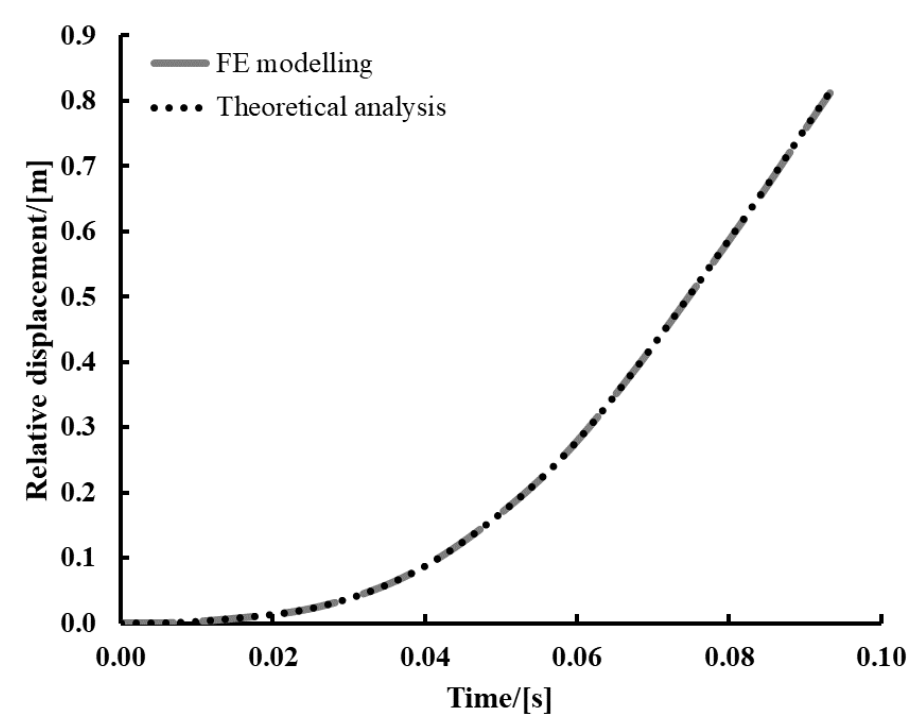

(b)

Fig. 10. (a) Finite element model of cantilever beam I; $(b)$ the relative displacement derived from FE modelling and theoretical calculation, respectively, when cantilever beam I subjects to the OCS of Fig. 3(b). 
The isodamage boundary associated with the critical stress is obtained by numerical simulation and plotted in Fig. 11 for rectangular cruash signal as a lower bound of the $A_{\max }-\Delta V$ diagram. This isodamage boundary can be divided into following three regimes,

408

- Regime I: $A_{\max }>9.0 \mathrm{~g}$, structural damage is controlled by both $A_{\max }$ and $\Delta V$, but $\Delta V=(\Delta V)_{c r} \approx$ $1.0 \times(9.8 \mathrm{~m} / \mathrm{s})$ obtained from Eq. (8) offers a lower bound, which is quite close to the iso-damage boundary in this regime;

- Regime II: $A_{\max } \leq 9.0 \mathrm{~g}$ and $\Delta V \leq 1.57 \times(9.8 \mathrm{~m} / \mathrm{s})$, structural damage is controlled by both $A_{\max }$ and $\Delta V$, and

- Regime III: $\Delta V>1.57 \times(9.8 \mathrm{~m} / \mathrm{s}), A_{\max }=A_{\max , c r} \approx 4.5 \mathrm{~g}$.

The OCS, EHSS (EHSS is used as ECS shown in Fig. 3(b)) and RSS of SCS-1 in Table 2 are shown by three points in Fig. 11, which fall into the non-damage region. In other words, the crash pulse, whose average acceleration is lower than $\left(\frac{1}{\pi}\right) \cdot A_{\max , c r} \cdot\left(\frac{f_{n}}{f_{s}}\right)^{-1}$, causes no damage to a cantilever beam with $\frac{f_{n}}{f_{s}} \approx \frac{1}{5}$. The OCS and ECS of SCS-2 to SCS-4 in Table 2 are also marked in Fig. 11, which fall into the damage region.

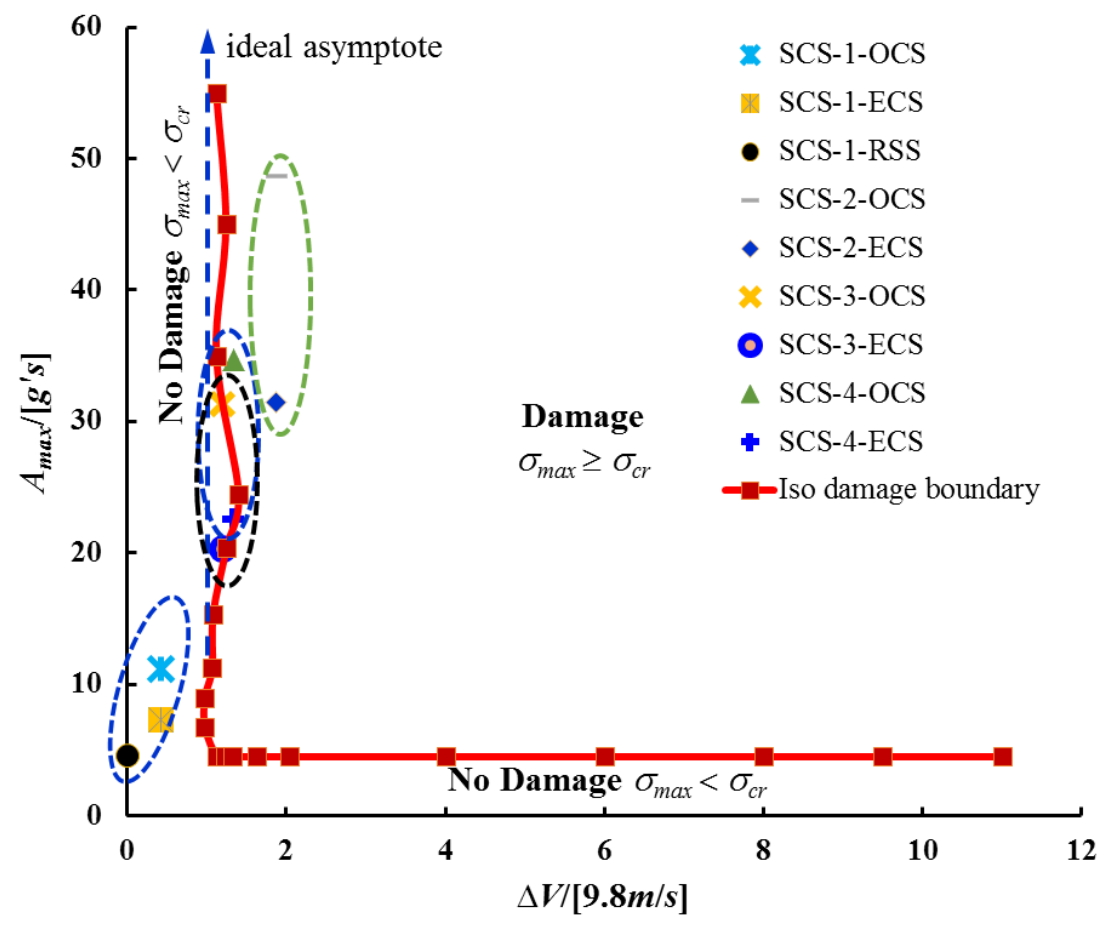

Fig. 11. The $A_{\max }-\Delta \mathrm{V}$ diagram derived from rectangular crash signal for beam I with $\sigma_{c r}=280 \mathrm{MPa}$, 
The upper bound of damage boundary is constructed by employing the PVSRS graph. The critical crash signals with the same shapes as ECS and RSS causing structural failure can be obtained by varing the coefficients of magnitudes until the $\sigma_{\max }$ equals failure stress of $280 \mathrm{MPa}$. It should be mentioned that the time duration remains unchanged to keep $\frac{f_{n}}{f_{s}}=5$. The upper bound of damage critical loadings, as shown in Fig. 12.

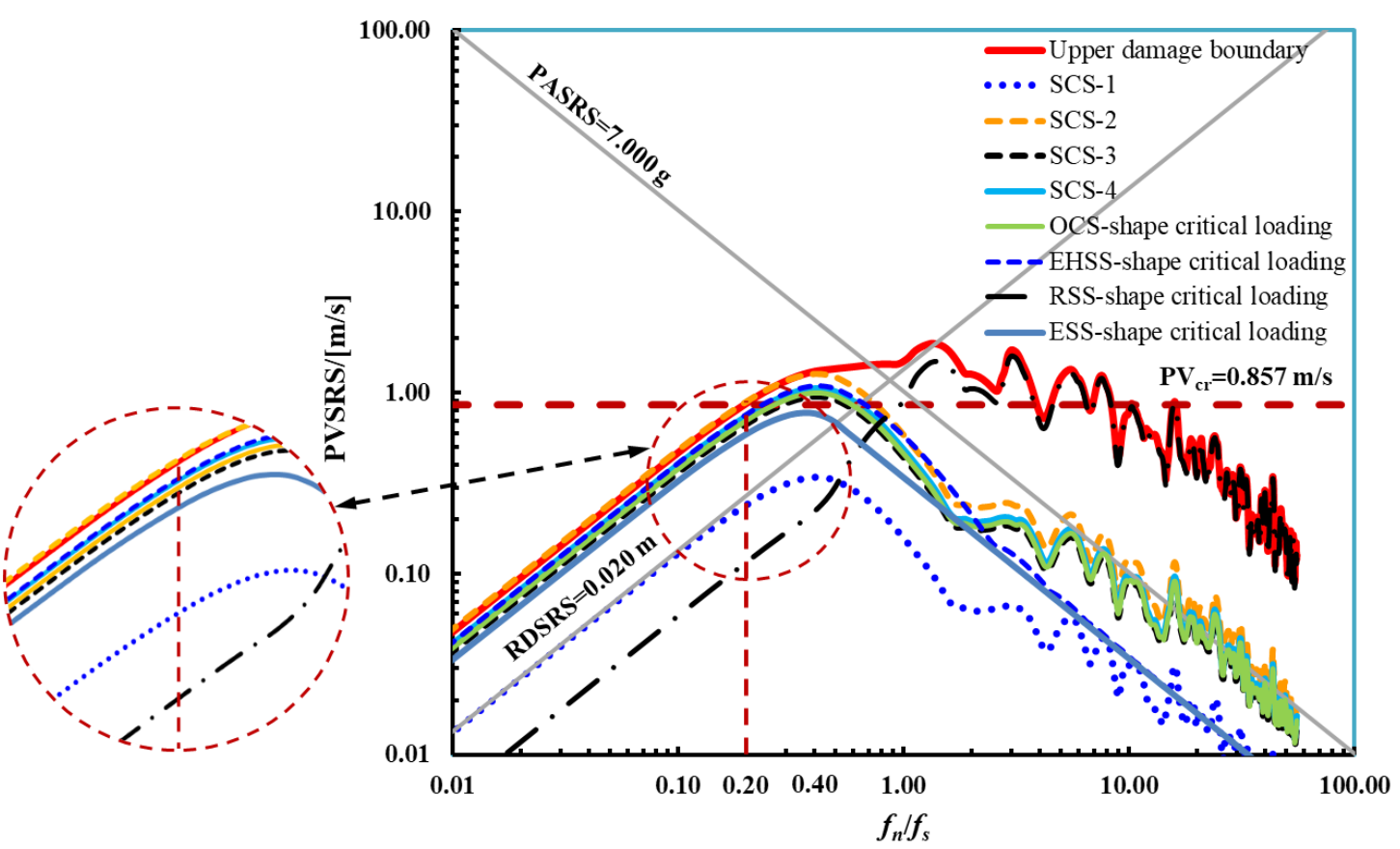

Fig. 12. PVSRS curves of the upper bound of damage boundary of beam I and various SCSs on a 4-coordinate graph.

The critical PVSRS curve derived from ESS-shape critical loading, i.e. $S_{c}$, is also ploted in Fig. 12. But, it should be noted that the overall lower bound of damage boundary is still defined by the ESS-based $A_{\max }-\Delta V$ diagram (shown in Fig. 11) for two main reasons, i.e. (i) the $A_{\max }-\Delta V$ diagram is not restricted to SDOF model, but can be established from simulations or experiments; (ii) the $A_{\max }-\Delta V$ diagram directly based on crash signals is easier for quick assessment. Therefore, the procedure of damage assessment is: (i) if the crash signal represented by a point $\left(\Delta \mathrm{V}, \mathrm{A}_{\max }\right)$ falls in the no damage area of ESS-based $\mathrm{A}_{\max }-\Delta \mathrm{V}$ diagram, then the structure is safe; (ii) if the crash signal falls in the damage area of $A_{\max }-\Delta V$ diagram, then the PVSRS graph is needed for further assessment.

440 Under this condition, the structure is still safe if the PVSRS of crash signal is lower than $S_{c}$ [13],

441 while the structure is damaged if the PVSRS of crash signal is higher than the upper bound of

442 damage boundary. The crash signal, whose PVSRS is above $S_{c}$ while below the upper bound of 
damage boundary (see the inset of Fig. 12), may or may not cause damage to the structure. The critical PVSRS curve derived from OCS-shape critical loading is also ploted in Fig. 12, which is located between the upper bound of damage boundary and $S_{c}$, as expected. According to the $S_{c}$ method in [13] (see Appendix), structural damage occurs when the PVSRS of a given crash signal at $f_{n} / f_{s}=0.2$ or in the range of $0.5-2$ times the $f_{n} / f_{s}=0.2$ is beyond the upper bound of damage boundary on PVSRS graph. The critical PVSRS at $f_{n} / f_{s}=0.2$, i.e. the PVSRS value of the upper bound damage boundary at $f_{n} / f_{s}=0.2$, is $\mathrm{PV}_{\text {cr }}=0.857 \mathrm{~m} / \mathrm{s}$, as shown in Fig. 12 .

The time histories of the maximum equivalent stress, i.e. von-Mises stress, for beam I under excitations of SCS- 1 and SCS- 4 are plotted in Fig. 13(b). The damage conditions evaluated by $\mathrm{A}_{\max }{ }^{-}$ $\Delta \mathrm{V}$ diagram, PVSRS graph and FE simulation are summarised in Table 5. For example, the maximum stress under SCS-1 is $95.97 \mathrm{MPa}(<280 \mathrm{MPa})$, which is consistent with the assessment based on both $\mathrm{A}_{\max }-\Delta \mathrm{V}$ diagram and PVSRS graph.

$\mathrm{MPa}$
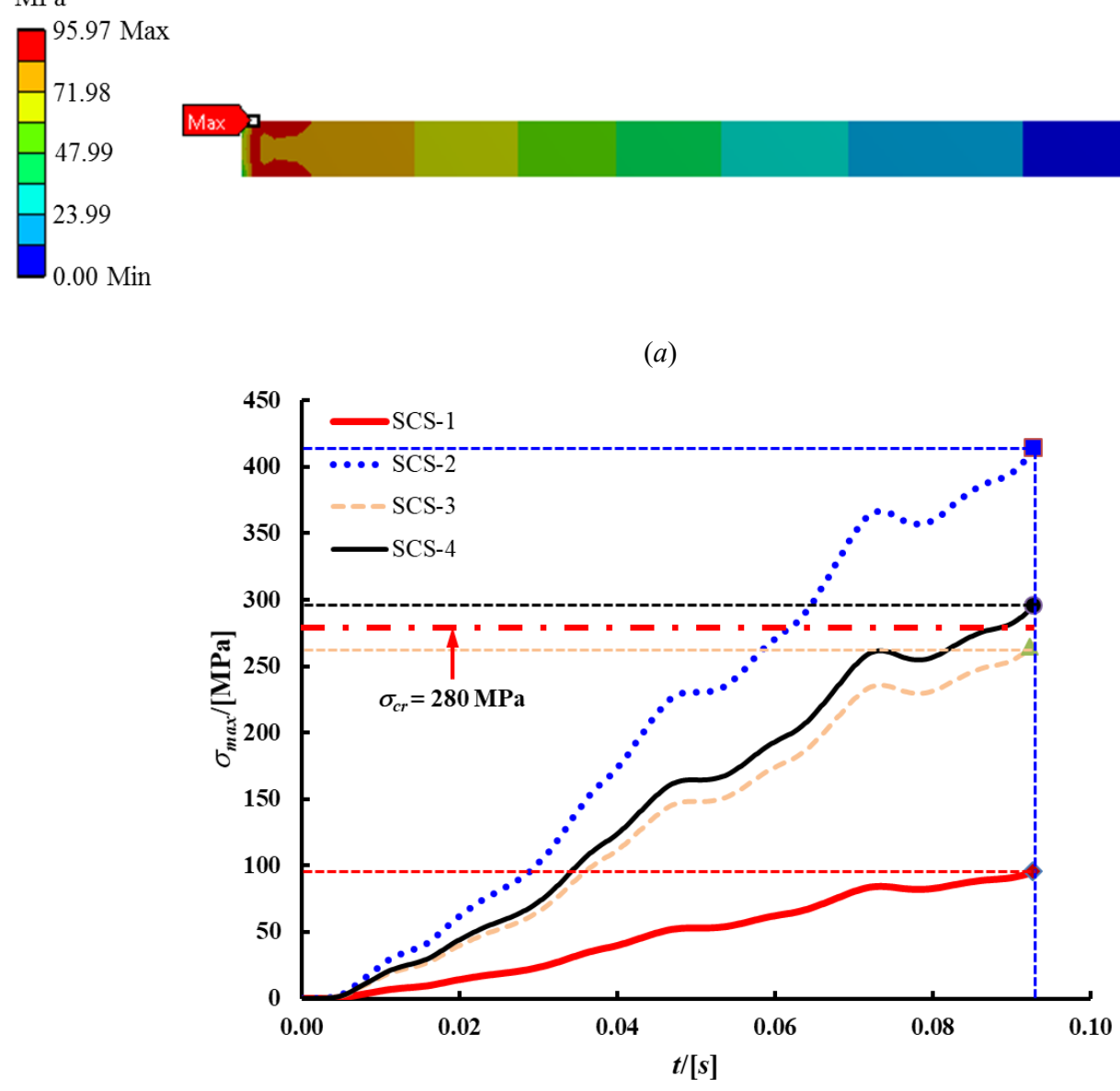

Fig. 13. The maximum equivalent stress for beam I: $(a)$ contour plot for SCS-1; $(b)$ time histories for 
Table 5. Results of the cantilever beam I with $\frac{f_{n}}{f_{S}} \approx \frac{1}{5}$ subjected to different SCSs.

\begin{tabular}{cccc}
\hline & \multicolumn{2}{c}{ Damage boundary } & \\
\cline { 2 - 3 } Base excitation, $\ddot{x}(t)$ & Lower boundary & Upper boundary & FE simulation \\
& $\left(\mathrm{A}_{\max }-\Delta \mathrm{V}\right)$ & (PVSRS) & \\
\hline SCS-1 & No damage & No damage & No damage \\
SCS-2 & Damage & Damage & Damage \\
SCS-3 & Damage & No damage & No damage \\
SCS-4 & Damage & No damage & damage \\
\hline
\end{tabular}

462

\subsection{Beam II with $f_{n} / f_{s} \approx 5$}

The first natrural frequency of beam II is $53.858 \mathrm{~Hz}$, i.e. $\frac{f_{n}}{f_{s}} \approx 5$. Responses of the cantilever beam are tabulted in Table 6, which reveals that the $|\ddot{y}|_{\max }$ and $|z|_{\max }$ derived from OCS and ECS are significantly different, although their relative difference values are slightly different from the results of SDOF in Table 1.

Table 6. Results of the cantilever beam II with $\frac{f_{n}}{f_{s}} \approx \mathbf{5}$ when subjected to base excitations in Fig. 3(b) (c).

\begin{tabular}{|c|c|c|c|c|c|}
\hline \multirow{2}{*}{$\begin{array}{l}\text { Natural frequencies of } \\
\qquad \text { Beam II }[\mathrm{Hz}]\end{array}$} & \multicolumn{4}{|c|}{ Structural response } & \multirow{2}{*}{$\begin{array}{c}\text { Relative difference } \\
\text { between OCS and ECS }\end{array}$} \\
\hline & & from OCS & from ECS & from RSS & \\
\hline \multicolumn{6}{|l|}{$f_{n 1}=53.858$} \\
\hline$f_{n 2}=336.615$ & $|\ddot{y}|_{\max }[\mathrm{g}]$ & 67.71 & 24.11 & 55.77 & $-64.39 \%$ \\
\hline \multicolumn{6}{|l|}{$f_{n 3}=944.052$} \\
\hline $\begin{array}{l}f_{n 4}=1851.383 \\
f_{n 5}=3060.138\end{array}$ & $|z|_{\max }[\mathrm{mm}]$ & 5.72 & 3.15 & 3.53 & $-44.98 \%$ \\
\hline
\end{tabular}

\section{(a) The lower bound of damage boundary based on $A_{\max }-\Delta V$ diagram}

The yield stress $\left(\sigma_{y}\right)$ of the cantilever beam is also defined as the critical stress, i.e. $\sigma_{\mathrm{cr}}=\sigma_{y}$, to determine the lower bound of damage boundary based on $A_{\max }-\Delta \mathrm{V}$ diagram. To construct the conservative isodamage boundary, the base excitation of rectangular crash signal is varied by changing its time duration $\left(t_{d}\right)$ and magnitude $\left(\mathrm{A}_{\max }\right)$. As shown in Fig. 14, the isodamage curve with critical stress obtained by numerical simulation is plotted in the $A_{\max }-\Delta \mathrm{V}$ diagram, where an isodamage boundary is divided into following three regimes,

- Regime I: $A_{\max }>226 \mathrm{~g}$, structural damage is controlled by both $A_{\max }$ and $\Delta V$, but $\Delta V=(\Delta V)_{c r} \approx$ 

this regime;

- Regime II: $A_{\max } \leq 226 \mathrm{~g}$ and $\Delta V \leq 1.57 \times(9.8 \mathrm{~m} / \mathrm{s})$, structural damage is controlled by both $A_{\max }$ and $\Delta V$, and

- Regime III: $\Delta V>1.57 \times(9.8 \mathrm{~m} / \mathrm{s}), A_{\max }=A_{\max , c r} \approx 113 \mathrm{~g}$.

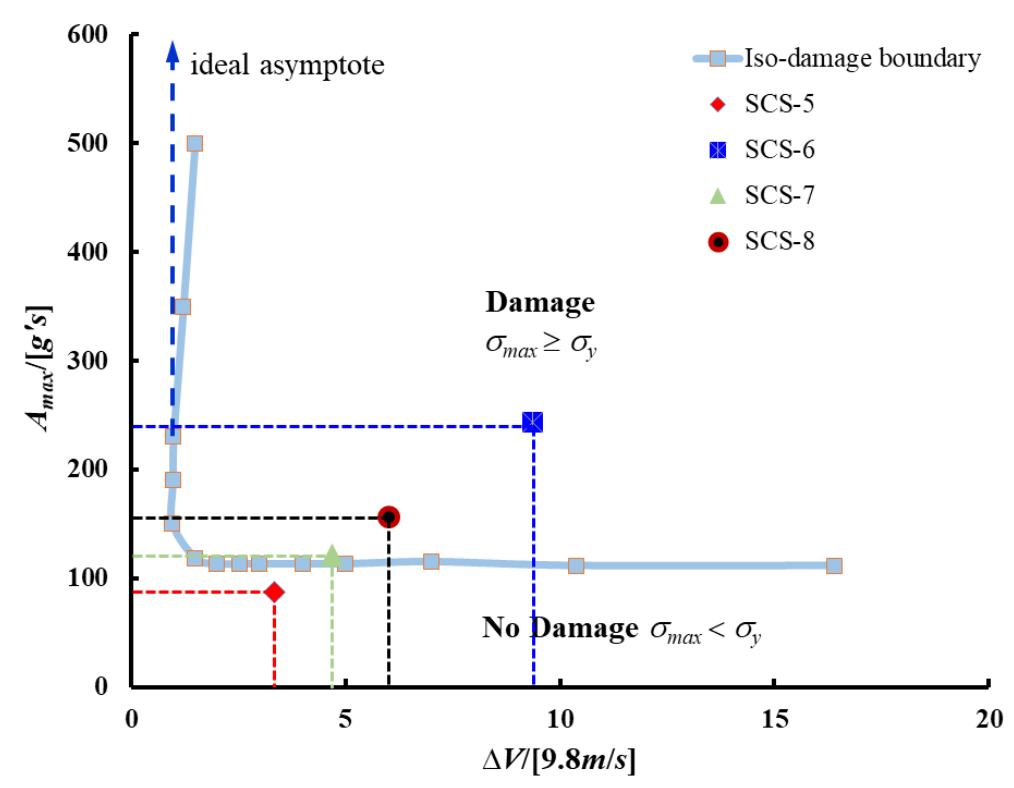

\section{(b) The upper bound of damage boundary based on PVSRS graph}

Similarly to the procedure in Section 4.1(b), the critical crash pulses with the same shapes as ECS and RSS causing structural failure can be obtained by varing the coefficients of magnitudes untill the $\sigma_{\max }$ equals $280 \mathrm{MPa}$, as shown in Fig. 15. Then, the upper bound of damage boundary and $S_{c}$ on PVSRS graph are constructed, which, together with the PVSRS curves of various crash signals, is shown in Fig.16. Same assessment procedure as that in Section 4.1(b) can be applied. The critical PVSRS at $f_{n} / f_{s}=5$ is $\mathrm{PV}_{\mathrm{cr}}=1.235 \mathrm{~m} / \mathrm{s}$. 


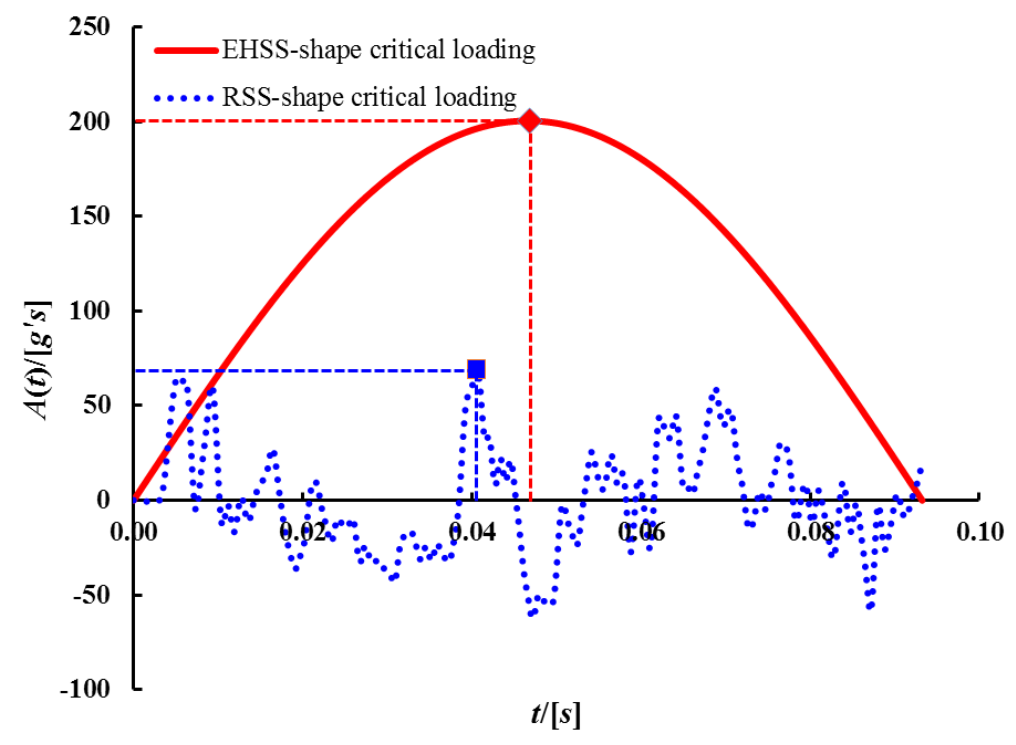

Fig. 15. The critical loadings with the same shapes as EHSS and RSS, respectively, causing structural failure.

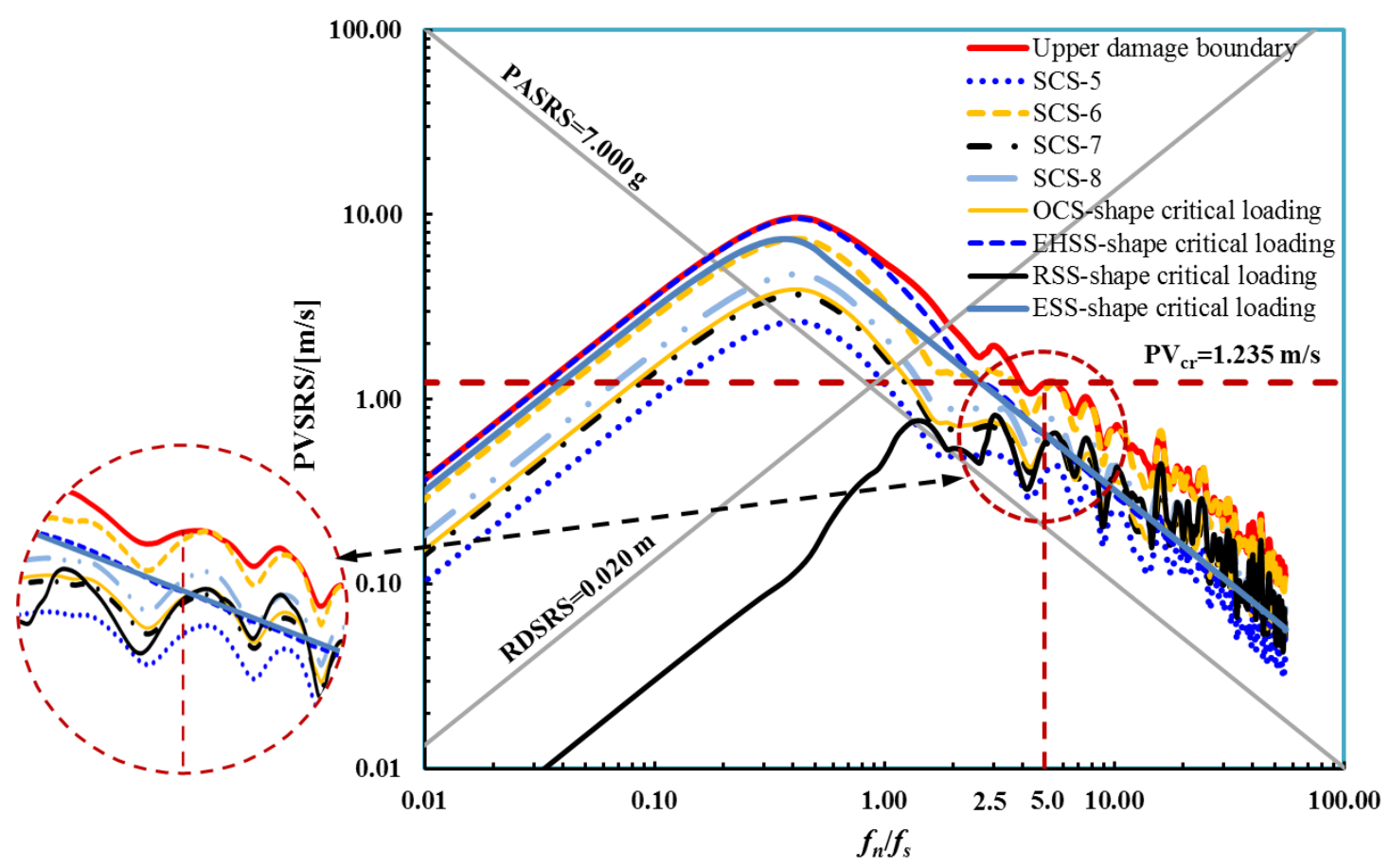

Fig. 16. PVSRS curves of the upper bound of damage boundary of beam II and various SCSs on a 4-coordinate

graph. understanding of the dual damage criteria. These SCSs are shown in $A_{\max }-\Delta V$ diagram in Fig. 14, while their corresponding PVSRS curves are plotted in Fig. 16. In addition, the time histories of the maximum equivalent stresses in beam II derived from different SCSs are illustrated in Fig. 17. Results of assessment are summarised in Table 7. 


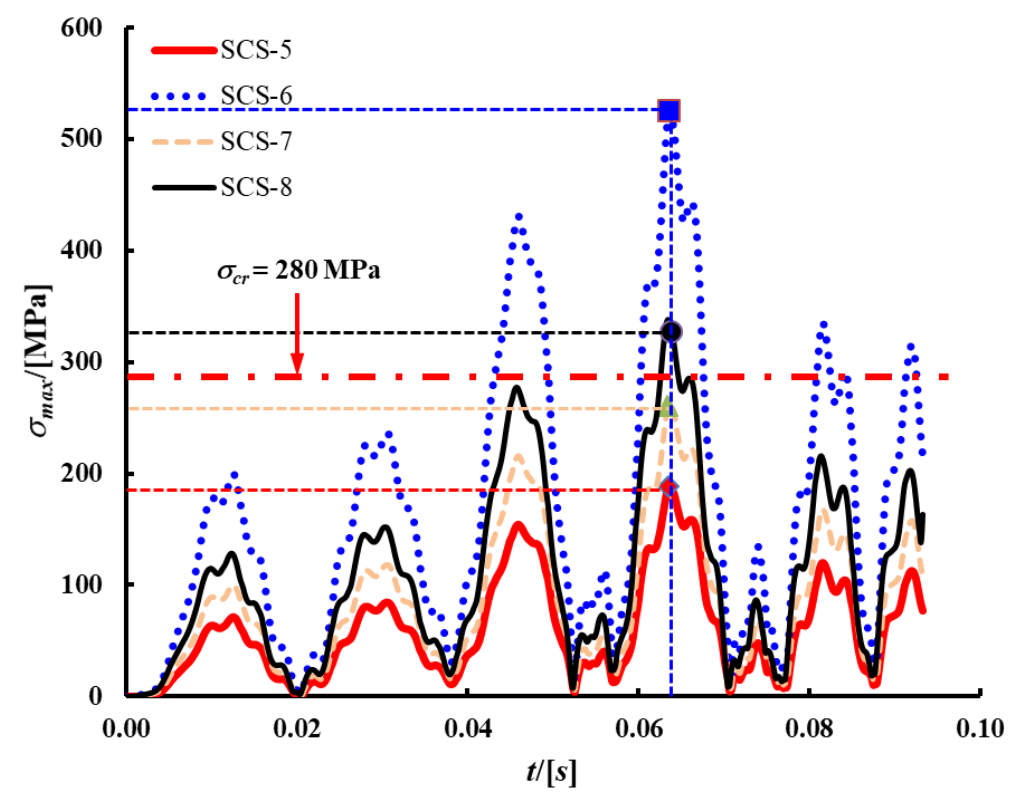

Fig. 17. The time histories of the maximum equivalent stresses in beam II derived from SCS-5 to SCS-8.

Table 7. Results of the cantilever beam II with $\frac{f_{n}}{f_{S}} \approx \mathbf{5}$ subjected to different SCSs.

\begin{tabular}{cccc}
\hline & \multicolumn{2}{c}{ Damage boundary } & \\
\cline { 2 - 3 } Base excitation, $\ddot{x}(t)$ & Lower boundary & Upper boundary & FE simulation \\
& $\left(\mathrm{A}_{\max }-\Delta \mathrm{V}\right)$ & (PVSRS) & \\
\hline SCS-5 & No damage & No damage & No damage \\
SCS-6 & Damage & Damage & Damage \\
SCS-7 & Damage & No damage & No damage \\
SCS-8 & Damage & No damage & damage \\
\hline
\end{tabular}

From Tables 5 and 7, we can obtain following conclusions:

(a) The structure is safe if the crash signal parameters locates under the lower bound of damage boundary on $\mathrm{A}_{\max }-\Delta \mathrm{V}$ diagram. For $\frac{f_{n}}{f_{S}} \leq \frac{1}{5}$, the base excitation can be represented by its ECS.

(b) When the crash signal paramters locate above the lower bound of damage boundary in $\mathrm{A}_{\max }-\Delta \mathrm{V}$ diagram, the structure is still safe if the PVSRS of the crash signal is lower than $S_{c}$ while the structure is damaged if the PVSRS of the crash signal is above the upper bound of damage boundary.

(c) The senarios outside senarios $(a)$ and $(b)$ are uncertain.

Overall, in addition to the existing standard testing methods in Appendix, the following 
additional test procedure for complex crash signals is proposed, i.e. (i) the lower bound of damage boundary in $\mathrm{A}_{\max }-\Delta \mathrm{V}$ diagram is constructed by following the same procedure in standard [13]; (ii) the OCS is decomposed to ECS and RSS by following the method of signal decomposition in Section 2.1; (iii) the magnitudes of ECS and RSS are scaled without changing the signal shape until the critical loadings that cause damage to the structure are obtained; (iv) PVSRS curves of critical ECS and RSS signals are calculated; (v) the upper bound of damage boundary in PVSRS graph as the summation of PVSRS curves of critical ECS and RSS signals can be derived; (vi) conduct the the assessment using dual damage criteria with $\mathrm{A}_{\max }-\Delta \mathrm{V}$ diagram and PVSRS graph.

\section{Conclusions}

The assessment of structural damage in a crash-stop incident is investigated based on the decomposition of crash signal, in which the OCS is separated into a smooth ECS and an oscillatory RSS. The shock effects on the responses of structures with various frequency ratios $\left(\frac{f_{n}}{f_{s}}\right)$ are analysed. The method of dual damage criteria is proposed by combining characteristics of the $\mathrm{A}_{\max }-\Delta \mathrm{V}$ diagram and PVSRS graph, in which a lower bound of damage boundary is constructed in $\mathrm{A}_{\max }-\Delta \mathrm{V}$ diagram while the PVSRS graph is used to assess the structural damage when the parameters of the crash signal is above the $\mathrm{A}_{\max }-\Delta \mathrm{V}$ diagram. In addition to the $S_{c}$ method recommended by ASTM D3332-99, an upper bound of damage boundary is proposed on PVSRS graph to further reduce the uncertainty of the damage assessment. It is found that the ECS is able to represent the OCS if the structure's natural frequency is relatively low compared with the effective frequency of the crash signal, i.e. $\frac{f_{n}}{f_{s}} \leq \frac{1}{5}$. Under this condition, no damage will occur if $A_{\text {avg }} \leq\left(\frac{1}{\pi}\right) \cdot A_{\max , c r} \cdot\left(\frac{f_{n}}{f_{s}}\right)^{-1}$. Otherwise, for $\frac{f_{n}}{f_{s}}>\frac{1}{5}$, the ECS cannot represent the OCS, and the OCS should be assessed. In this case, the dual damage criteria on $\mathrm{A}_{\max }-\Delta \mathrm{V}$ diagram and PVSRS graph can be applied to provide more accurate damage assessment for crash signals. This study underpins the mechanics principles to support further improvement of the relevant standards for the damage assessment of occupied structures subjected to crash loads.

\section{Acknowledgments}

The first author would like to acknowledge the Joint Scholarship between China Scholarship 544 Council (CSC) and The University of Manchester for PhD study (No. 201706370205). 

[13]. Two test methods (i.e. Test Method A and Test Method B) are introduced for the determination of the shock fragility of products. A damage boundary (i.e. the $\mathrm{A}_{\max }-\Delta \mathrm{V}$ diagram) and a "critical" SRS plot $\left(S_{c}\right)$ are adopted to assess the damage condition of products.

Test Method A is used firstly to determine the critical velocity change, $(\Delta \mathrm{V})_{\mathrm{cr}}$, of the product in Regime I of the $\mathrm{A}_{\max }-\Delta \mathrm{V}$ diagram. The procedure is described by: (a) Set the shock test machine so that the shock signal produced has a velocity change below the anticipated $(\Delta \mathrm{V})_{\mathrm{cr}}$ of the product; (b) Perform one shock test and determine whether damage due to shock has occurred; (c) If no damage has occurred, set the shock test machine for a higher velocity change and repeat the shock test until product damage occurs. Thus, the $(\Delta \mathrm{V})_{\text {cr }}$ is obtained. Half-sine shock signals are normally used to perform this test since they are relatively easy to control.

Test Method B is used secondly to determine the critical acceleration, $A_{\text {max,cr }}$, of the product in Regime III of the $\mathrm{A}_{\max }-\Delta \mathrm{V}$ diagram. The procedure is described by: (a) Set the shock test machine so that it will produce a shock signal having a velocity change of at least $1.57 \cdot(\Delta \mathrm{V})_{c r}$ determined in Test Method A (see Fig. 7 for the position of $v=1.57 \cdot v_{c r}$ ), while the maximum acceleration $\left(A_{\max }\right)$ level of the first shock signal should be below the anticipated $A_{\max , \mathrm{rr}}$; $(b)$ Perform one shock test and determine whether damage due to shock has occurred; (c) If no damage has occurred, set the shock test machine for a higher $\mathrm{A}_{\max }$ and repeat the shock test until product damage occurs. Thus, the critical shock loading and its corresponding $\mathrm{A}_{\max , \mathrm{cr}}$ are obtained. Trapezoidal shock signals with very short rise and fall times are normally used to perform this test since it can be easily generated in a laboratory to approximate an ideal ESS. Therefore, the $A_{\max }-\Delta V$ diagram bounded by the critical velocity change and critical maximum acceleration for a given damage level can be established by following the above Test Methods A and B. The critical SRS curve $\left(S_{c}\right)$ can be derived from the critical shock loading determined by Test Method B. Although AASRS is used in D3332-99, it realises 'different types of SRS analyse, and therefore, other types of SRS are acceptable.

Product damage will not occur if (i) the shock signal represented by a point $\left(\mathrm{A}_{\max }, \Delta \mathrm{V}\right)$ falls in the no damage region in the critical $\mathrm{A}_{\max }-\Delta \mathrm{V}$ diagram; or (ii) the SRS of the shock signal (or base excitation) lies below the $S_{c}$ in a frequency range of approximately $\frac{1}{2}$ to 2 times the product's (dominant) natural frequency $\left(f_{n}\right)$.

\section{Abbreviations}

\begin{tabular}{ll}
\hline Abbreviation & Full name \\
\hline AA & Absolute acceleration
\end{tabular}


AASRS

APV

ASTM

ASTM D3332-99

EA

ECS

EHSS

EHVS

EITS

ENTS

EPTS

ESS

FFT

HIC

IEA

MCF

MDOF

OCS

PA

PASRS

PCF

PV

PVSRS

$\mathrm{RD}$

RDSRS

RSS

SCSs

SDOF

SEA

SRS

$T R$
Absolute acceleration SRS

Acceleration pseudo velocity

American Society for Testing and Materials

Standard Test Methods for Mechanical Shock Fragility

of Products

Energy absorption

Equivalent crash signal

Equivalent half-sine signal

Equivalent haversine signal

Equivalent isosceles triangular signal

Equivalent negative triangular signal

Equivalent positive triangular signal

Equivalent square signal

Fast Fourier transform

Head injury criterion

Impact energy absorbers

Mean crushing force

Multi-degree-of-freedom

Original crash signal

Pseudo acceleration

Pseudo-acceleration SRS

Peak crushing force

Pseudo velocity

Pseudo-velocity SRS

Relative displacement

Relative displacement SRS

Residual shock signal

Scaled crash signals

Single-degree-of-freedom

Specific energy absorption

Shock response spectrum

Transmissibility 


\begin{tabular}{|c|c|}
\hline Notation & Description \\
\hline$A(t)$ & Acceleration-time history (or deceleration-time history) \\
\hline$A_{1}(t)$ & Equivalent crash signal \\
\hline$A_{2}(t)$ & Residual shock signal \\
\hline$a$ & Normalised maximum acceleration \\
\hline$A_{\text {avg }}$ & Average (or mean) acceleration \\
\hline$a_{\text {avg }}$ & Normalised average acceleration \\
\hline$a_{c r}$ & Normalised critical maximum acceleration \\
\hline$A_{\max }$ & Maximum acceleration \\
\hline$A_{\max }-\Delta \mathrm{V}$ diagram & Maximum acceleration-velocity change diagram \\
\hline $\mathrm{A}_{\text {max,cr }}$ & Critical maximum acceleration \\
\hline$c$ & Damping coefficient \\
\hline \multirow{2}{*}{$f_{1}$} & The nonzero frequency corresponding to the highest \\
\hline & amplitude from the FFT of OCS \\
\hline \multirow{2}{*}{$f_{2}$} & The nonzero frequency corresponding to the next highest \\
\hline & amplitude from the FFT of OCS \\
\hline$f_{L}$ & Low-pass filter frequency \\
\hline$f_{n}$ & Natural frequency \\
\hline$f_{s}$ & Effective frequency \\
\hline$g$ & Standard gravity acceleration \\
\hline$I_{m}$ & Area moment of inertia \\
\hline$k$ & Stiffness \\
\hline$m$ & Mass \\
\hline$p-i$ diagram & Pressure-impulse diagram \\
\hline $\mathrm{PV}_{\mathrm{cr}}$ & Critical pseudo velocity \\
\hline$r$ & Modal participation factor \\
\hline$S_{c}$ & Critical SRS \\
\hline$t$ & Time \\
\hline$t_{d}$ & Overall time duration of the crash signal \\
\hline$v$ & Normalised velocity change \\
\hline$v_{\text {cr }}$ & Normalised critical velocity change \\
\hline \multirow{2}{*}{$\ddot{x}(t)$} & Acceleration-time history acting on the base of SDOF \\
\hline & model \\
\hline$\ddot{y}$ & The output absolute acceleration of SDOF model \\
\hline$z=y-x$ & The relative displacement \\
\hline
\end{tabular}




\begin{tabular}{ll}
\hline$z_{c r}$ & Critical relative displacement \\
$z_{\text {max }}$ & Maximum relative displacement \\
$\Delta \mathrm{V}$ & Velocity change \\
$(\Delta V)_{c r}$ & Critical velocity change \\
$\lambda_{1}, \lambda_{2}$ & Characteristic frequency ratios \\
$v$ & Poisson's ratio \\
$\xi$ & Damping ratio \\
$\rho$ & Density \\
$\sigma_{\mathrm{cr}}$ & Critical stress \\
$\sigma_{y}$ & Yield stress \\
$\omega$ & The angular frequency of harmonic excitation \\
$\omega_{n}$ & The angular frequency of structure \\
\hline
\end{tabular}

\section{References}

[1] Zhou CY, Yu TX, Lee RS. Drop/impact tests and analysis of typical portable electronic devices. Int J Mech Sci 2008;50(5):905-17.

[2] Vergnolle JF. Soft landing impact attenuation techologies review. In13th Aerodynamic Decelerator Systems Technology Conference 1995;1535.

[3] Wei J, Cao D, Wang L, Huang H, Huang W. Dynamic modeling and simulation for flexible spacecraft with flexible jointed solar panels. Int J Mech Sci 2017;130:558-70.

[4] Aquaro D, Zaccari N, Di Prinzio M, Forasassi G. Numerical and experimental analysis of the impact of a nuclear spent fuel cask. Nucl Eng Des 2010;240(4):706-12.

[5] Mines RA. Strain rate effects in crushable structural foams. Appl Mech Mater 2007;7:231-36.

[6] Yang C, Li QM. Structural optimisation for the collapse zone of a railway vehicle. Int J Mech Sci 2020;165:105201.

[7] Fasanella EL, Jackson KE. Impact testing and simulation of a crashworthy composite fuselage section with energy-absorbing seats and dummies. J Am Helicopter Soc 2004;49(2):140-8.

[8] Zhou Z, Griffin MJ. Response of the seated human body to whole-body vertical vibration: discomfort caused by mechanical shocks. Ergonomics 2017;60(3):347-57.

594 [9] Newton RE. Fragility assessment theory and test procedure, Monterey Research Laboratory, Inc 1968.

595 [10] Jarrett DF. Derivation of British explosives safety distances. Annuals of the New York Academy of Science $1968 ; 152: 18-35$.

[11] Li QM, Meng H. Pressure-impulse diagram for blast loads based on dimensional analysis and single-degreeof-freedom model. J Eng Mech 2002;128(1):87-92. 
[12] Abedini M, Mutalib AA, Raman SN, Alipour R, Akhlaghi E. Pressure-impulse (P-I) diagrams for reinforced concrete (RC) structures: A review. Arch Comput Methods Eng 2018;1-35.

[13] ASTM D3332-99, Standard Test Methods for Mechanical-Shock Fragility of Products, Using Shock Machines, ASTM International, West Conshohocken, PA, 2016.

[14] Grady D. Physics of Shock and Impact (Vol. 1). IOP Publishing, 2017.

[15] Xi CQ, Li QM. Meso-scale mechanism of compaction shock propagation in cellular materials. Int J Impact Eng 2017;109:321-34

[16] Gharaibeh MA, Su QT, Pitarresi JM. Analytical model for the transient analysis of electronic assemblies subjected to impact loading. Microelectron Reliab 2018;91:112-9.

[17] Biot MA. Transient oscillations in elastic systems. Calif Inst Technol 1932.

[18] Goyal S, Buratynski EK, Elko GW. Role of shock response spectrum in electronic product suspension design. Int J Microcircuits Electron Package 2000;23(2):182-90.

[19] Navuri K, Prakash D, Mani PB, Kumar AE. Shock response analysis of mechanical hardware of flight data recorder. Mater Today Proc 2017;4(8):8000-9.

[20] Li BW, Li QM. Damage boundary of structural components under shock environment. Int J Impact Eng 2018;118:67-77.

[21] Wijker JJ. Spacecraft structures. Springer Science \& Business Media, 2008.

[22] Irvine T. An introduction to the shock response spectrum. Rev P, Vibrationdata, 2012.

[23] Kipp WI. Developments in testing products for distribution. Packag Technol Sci 2000;13(3):89-98.

[24] Qian J, Cai H, Ma W, Hao Z. Shock analysis on a packaged washing machine from damage boundary: shock response spectrum to component failure. Shock Vib 2015;462492.

[25] Song XG, Sun GY, Li GY, Gao WZ, Li Q. Crashworthiness optimization of foam-filled tapered thin-walled structure using multiple surrogate models. Struct Multidisc Optim 2013;47(2):221-31.

[26] Yang CX, Xu P, Yao SG, Xie SC, Li QM, Peng Y. Optimization of honeycomb strength assignment for a composite energy-absorbing structure. Thin-Walled Struct 2018;127:741-55.

[27] Hanssen AG, Langseth M, Hopperstad OS. Static and dynamic crushing of circular aluminium extrusions with aluminium foam filler. Int J Impact Eng 2000;24(5):475-507.

[28] Jones N. Energy-absorbing effectiveness factor. Int J Impact Eng 2010;37(6):754-65.

[29] Reddy TJ, Narayanamurthy V, Rao YV. Evolution of a new geometric profile for an ideal tube inversion for crash energy absorption. Int J Mech Sci 2019;155:125-42.

[30] Maheras SJ, Lahti EA, Ross SB. Transportation shock and vibration literature review. Pacific Northwest National Lab.(PNNL), Richland, WA (United States), 2013.

[31] Ross SB, Best RE, Klymyshyn NA, Jensen PJ, Maheras SJ. Used fuel rail shock and vibration testing options analysis. Pacific Northwest National Lab.(PNNL), Richland, WA (United States), 2014.

[32] Cummings AD. Characterising the mechanical loads acting on nuclear packages during rail transportation (PhD thesis). Liverpool John Moores University; 2004. 
635 [33] Foley JT, Gens MB. Shock and vibration measurements during normal rail and truck transport (No. CONF-

636710801 (Vol. 2)). Sandia National Laboratory 1971.

637 [34] Magnuson CF. Shock and vibration environments encountered during normal rail transportation of heavy cargo 638 (No. SAND-82-0819; TTC-0298). Sandia National Laboratory 1982.

639 [35] Wang CY, Li YB, Huang SL. Analysis of shock pulses in passive safety tests for automotive vehicle using 640 shock response spectrum. Veh Technol 1995;9:23-27. (in Chinese)

641 [36] ECE U. Uniform provisions concerning the approval of vehicles with regard to the protection of occupants in 642 the event of a lateral collision, Regulation No. 95. Geneva: UN ECE 1995.

643 [37] Huang M. Vehicle crash mechanics. CRC press, 2002.

644 [38] Varat MS, Husher SE. Crash pulse modelling for vehicle safety research. Proc: Int Tech Conf Enhanced Saf 645 Veh, National Highway Traffic Safety Administration 2003.

[39] Chopra AK. Dynamics of structures: theory and applications to earthquake engineering (4th edition). Prentice 647 Hall; 2012.

648 [40] Goyal S, Papadopoulos JM, Sullivan PA. Shock protection of portable electronic products: shock response spectrum, damage boundary approach, and beyond. Shock Vib 1997;4(3):169-91.

650

[41] Irvine T. Effective modal mass and modal participation factors (Revision I). 2015, http://www.vibrationdata.com/tutorials2/ModalMass.pdf, retrieved on 07/01/2020.

652 [42] Irvine T. Modal transient vibration response of a cantilever beam subjected to base excitation. 2013, http://citeseerx.ist.psu.edu/viewdoc/download?doi=10.1.1.570.4142\&rep=rep1\&type=pdf, $\quad$ retrieved on $07 / 01 / 2020$. $\underline{\text { https://vibrationdata.wordpress.com/2016/08/30/matlab-batch-process-via-vibrationdata-gui/, }}$ retrieved on 07/01/2020. 